Review Paper

\title{
Biogenic copper nanoparticles and their applications: A review
}

\author{
Mostafa F. Al-Hakkani ${ }^{1}$ [D
}

Received: 17 November 2019 / Accepted: 17 February 2020 / Published online: 28 February 2020

(c) Springer Nature Switzerland AG 2020

\begin{abstract}
The objective of the present work is the introduction of a quick and simple literature survey about the green bio-synthesized of copper nanoparticles. The survey revealed that the eco-friendly preparation methods using different plant species, properties and potential applications as alternative promising for silver and gold nanoparticles. The review enumerates the classification of nanomaterials in general, green biosynthesis of nanoparticles using plant extracts and its advantages over using bacteria and fungi. The manuscript gives more details about the specific properties for copper nanoparticles as optical properties of copper nanoparticles especially surface plasmon resonance in the visible range, photoluminescence, and bandgap energy. The current review spotlights and focuses on antimicrobial and anticancer activities for copper nanoparticles against several and various types of gram-negative, gram-positive bacteria, fungi, and human cell cancers. Moreover, a new promising activity as adsorptive efficiency of copper nanoparticles for wastewater treatment was revealed.
\end{abstract}

Keywords Nanoparticles · Biosynthesis · Copper · Anti-cancer · Anti-microbial · Adsorption

$\begin{array}{ll}\text { Abbreviations } \\ \mathrm{E}_{\mathrm{g}} & \text { Energy band gap } \\ \text { B. subtilis } & \text { Bacillus subtilis bacteria } \\ \text { C. albicans } & \text { Candida albicans fungi } \\ \text { Caco-2 } & \text { Human colorectal adenocarcinoma cells } \\ \text { Cu NPs } & \text { Copper nanoparticles } \\ \text { E. coli } & \text { Escherichia coli bacteria } \\ \text { FT-IR } & \text { Fourier-transform infrared } \\ \text { HepG2 } & \text { Human hepatocellular carcinoma cells } \\ \text { HPLC } & \text { High performance liquid } \\ & \text { chromatography } \\ \text { IC } & \text { Half maximal inhibitory concentration } \\ \text { Mcf-7 } & \text { Human breast cancer cells } \\ \text { NIR } & \text { Near-infrared } \\ \text { NMs } & \text { Nanomaterials } \\ \text { NPs } & \text { Nanoparticles } \\ \text { P. aeruginosa } & \text { Pseudomonas aeruginosa bacteria } \\ \text { PL } & \text { Photoluminescent } \\ \text { S. aureus } & \text { Staphylococcus aureus bacteria } \\ \text { SEM } & \text { Scanning electron microscopy }\end{array}$

$\begin{array}{ll}\text { SPR } & \text { Surface plasmon resonance } \\ \text { TEM } & \text { Transmission electron microscopy } \\ \text { UV-Vis } & \text { Ultraviolet-visible } \\ \text { XRD } & \text { X-ray diffraction }\end{array}$

\section{Introduction}

\subsection{Nanoscience and Nanotechnology}

Nanoscience is the studying science of materials and structures at $10^{-9}$ of the scale. "The properties of matter at the nanoscale are different from those at a larger scale. When the dimensions of a material are reduced from a large size, the properties remain the same at first, and then small changes occur. Finally, when the size drops below $100 \mathrm{~nm}$, dramatic changes in properties can occur" [1].

Nanoscience can be defined as the study of phenomena and manipulation of materials at atomic, molecular and macromolecular scales, where properties differ

Mostafa F. Al-Hakkani, mostafa.f@scinv.au.edu.eg| ${ }^{1}$ Chemistry Department, Faculty of Science, New Valley University, Al-Kharja 72511, Egypt. 
significantly from those at a larger scale; and nanotechnologies as the design, characterization, production, and application of structures, devices, and systems by controlling shape and size at the nanometer scale [2].

Nanotechnology refers to any technology that is implemented at the nanoscale and has actual applications. It is defined as the control or restructuring of matter at the atomic and molecular levels in the size range of about $1-100 \mathrm{~nm}[1]$.

"The two main reasons for the change in behavior from bulk state to nano state are an increased relative surface area and the dominance of quantum effects. An increase in surface area (per unit mass) will result in a corresponding increase in chemical reactivity, making some nanomaterials useful as catalysts to improve the efficiency of fuel cells and batteries" [3]. As the size of the matter is reduced to tens of nanometers or less, quantum effects can begin to play a role, and these can significantly change a material's optical, magnetic or electrical properties [3]. In some cases, size-dependent properties have been exploited for centuries. For example, gold and silver nanoparticles have been used as colored pigments in stained glass and ceramics since the tenth century [4]. Depending on their size, gold particles can appear red, blue or gold in color [5, 6]. The challenge for the ancient chemists was to make all nanoparticles at the same size (and hence the same color), and the production of single-size nanoparticles is still a challenge today [6].

"The unique physical and chemical properties of nanomaterials can be used in commercial applications and for novel performance that benefits society. The discovery of novel materials, processes, and phenomena at the nanoscale and the development of new experimental and theoretical techniques for research at the end of the twentieth century provide fresh opportunities for the development of innovative Nanosystems and nanomaterials. This field is opening new avenues in science and technology" [1].

\subsection{Nanoscale}

The word "nano" stems from the Greek word "Nanos", which means dwarf [7]. This word "nano" has been assigned to indicate the number $10^{-9}$, i.e., one billionth of any unit. A nanometer $(\mathrm{nm})$ is one thousand millionth of a meter $\left(10^{-9} \mathrm{~m}\right)$. For comparison, a single human hair is about $80,000 \mathrm{~nm}$ wide, a red blood cell is approximately $7000 \mathrm{~nm}$ wide and a water molecule is almost $0.3 \mathrm{~nm}$ across. Examples for nanostructures on nanoscale was shown in Fig. 1. People are interested in the nanoscale (which is defined to be from $100 \mathrm{~nm}$ down to the size of atoms; approximately $0.2 \mathrm{~nm}$ ) because it is at this scale the properties of materials can be very different from those at a larger scale [8].

\subsection{Nanostructures}

Nanostructured materials (NSMs) represent an active area of research and a techno-economic sector with full expansion in many application fields. NSMs have gained its importance in technological advancements due to their tunable physicochemical characteristics such as melting point, wettability, electrical and thermal conductivity,

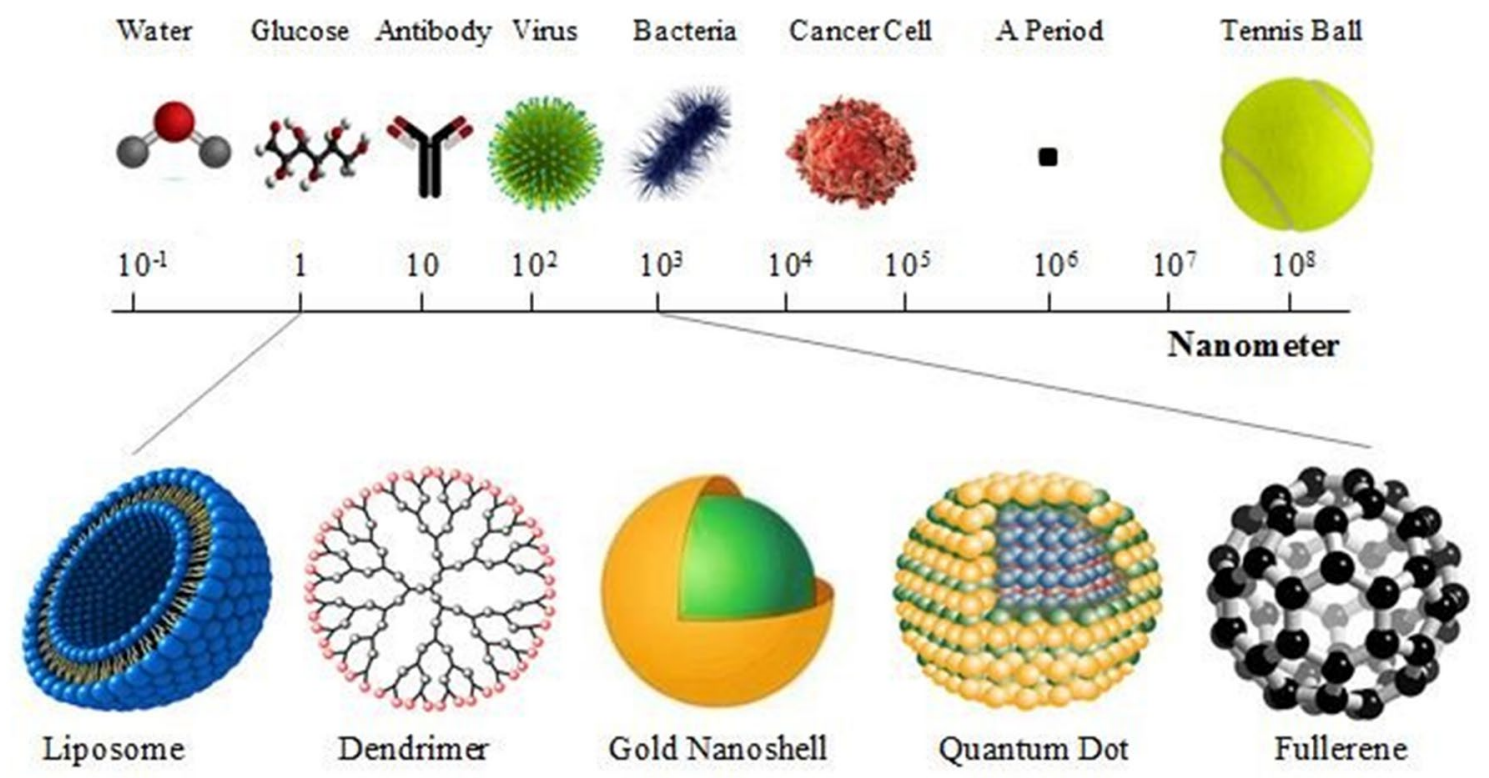

Fig. 1 Nanoscale and nanostructure diagram [9] 
catalytic activity, light absorption and scattering resulting in enhanced performance over their bulk states. NMs can be defined as"materials that have at least one dimension in the range of approximately $1-100 \mathrm{~nm}$ and exhibit dimension-dependent phenomena". Another definition can be used for NMs" material with any external nanoscale dimension or having the internal nanoscale surface structure". Nanofibers, nanoplates, nanowires, quantum dots, and other related terms have been defined based on this ISO definition. Likewise, the term nanomaterial is described as "a manufactured or natural material that possesses unbound, aggregated or agglomerated particles where external dimensions are between 1 and $100 \mathrm{~nm}$ size range" [10]. The most successful examples are seen in the microelectronics, where "smaller" has always meant a greater performance ever since the invention of transistors: e.g. higher density of integration, faster response, lower cost, and less power consumption [11].

Today manufactured NMs can significantly improve the characteristics of bulk materials, in terms of strength, conductivity, durability, and lightness, and they can provide useful properties (e.g., self-healing, self-cleaning, antifreezing, and antibacterial) and can function as reinforcing materials for construction or sensing components for safety.

\subsection{Classification of nanomaterials}

\subsubsection{According to the material- based}

1.4.1.1 Carbon-based nanomaterials Generally, these NSMs contain carbon and are found in morphologies such as hollow tubes or spheres. Fullerenes (C60), carbon nanotubes (CNTs), carbon nanofibers, carbon black, and graphene (Gr). Laser ablation, arc discharge, and chemical vapor deposition (CVD) are the important production methods for these carbon-based materials fabrication (except carbon black) [10].

1.4.1.2 Inorganic-based nanomaterials These NSMs can be synthesized into metals such as $\mathrm{Au}, \mathrm{Ag}$ or $\mathrm{Cu}$ NPs, metal oxides such as $\mathrm{TiO}_{2}$ and $\mathrm{ZnO}$ NPs, and semiconductors such as silicon and ceramics [10].

1.4.1.3 Organic-based nanomaterials These include NSMs made mostly from organic matter, excluding carbonbased or inorganic-based NSMs. The utilization of noncovalent (weak) interactions for the self-assembly and design of molecules helps to transform the organic NSMs into desired structures such as dendrimers, micelles, liposomes, and polymer NPs [10].
1.4.1.4 Composite-based nanomaterials Composite NSMs are multiphase NPs and NSMs with one phase on the nanoscale dimension that can either combine NPs with other NPs or NPs combined with larger or with bulk-type materials (e.g., hybrid nanofibers) or more complicated structures, such as a metal-organic framework.

The composites may be any combinations of carbonbased, metal-based, or organic-based NSMs with any form of metal, ceramic, or polymer bulk materials. NSMs are synthesized in different morphologies depending on the required properties for the desired application [10], as shown in Figs. 2, 3 and 4.

\subsubsection{According to their dimensions}

The first classification idea of NSMs was given by Gleiter [15], where NSMs were classified depending on their crystalline forms and chemical composition. It was explained by Skorokhod [16]. However, the Skorokhod scheme was not fully considered because of $0 D, 1 D, 2 D$, and 3D structures "Dimensionality of the NPs and NSMs" such as fullerenes, nanotubes, and nanoflowers were not taken into account. However, Pokropivny and Skorokhod [17] reported a modified classification scheme for NSMs, in which 0D, 1D, 2D, and 3D NSMs are included, as shown in Figs. 2, 3 and 4. This classification is highly dependent on the electron movement along the dimensions in the NMs. For example, electrons in 0D NMs are entrapped in a dimensionless space whereas 1D NMs have electrons that can move along the $x$-axis, which is less than $100 \mathrm{~nm}$. Likewise, 2D and 3D NMs have electron movement along the $x$-y-axis, and $x, y, z$-axis respectively.

A major feature that discriminates various types of nanostructures is their dimensionality. In the past 20 years, significant progress has been made in the field of OD NSMs. A rich variety of physical and chemical methods have been developed for fabricating OD NMSs with well-controlled dimensions. OD NSMs such as uniform particles arrays as quantum dots, heterogeneous particle arrays, core-shell quantum dots, onions, hollow spheres, and nano lenses have been synthesized by several research groups [18-22]. Figure 5 shows the images of different types of OD NSMs.

\subsubsection{According to their origin}

1.4.3.1 Natural nanomaterials They are produced in nature either by biological species or through anthropogenic activities. The production of artificial surfaces with exclusive micro and nanoscale templates and properties for technological applications are readily available from natural sources. Naturally occurring NMs are present through the Earth's spheres (i.e., in the hydrosphere, 
Fig. 2 Nanomaterials with different morphologies: a nonporous Pd NPs (OD), b

Graphene nanosheets (2D), c Ag nanorods (1D), d polyethylene oxide nanofibers (1D), e urchin-like $\mathrm{ZnO}$ nanowires (3D), $\mathbf{f} \mathrm{WO}_{3}$ nanowire network (3D) [10]

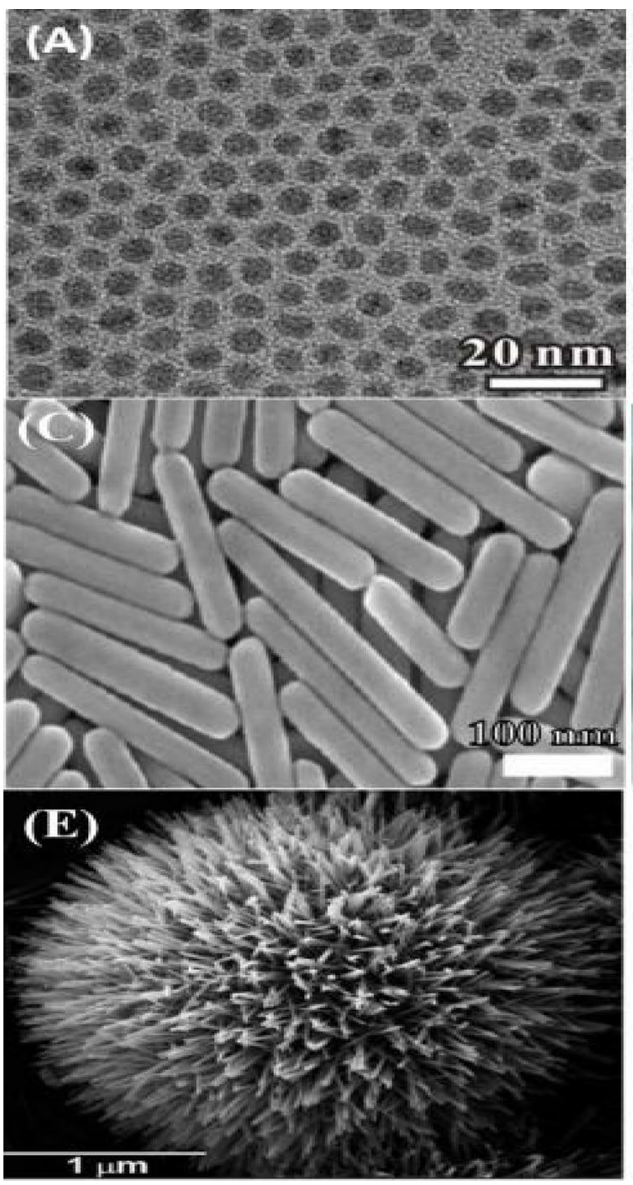

\section{(B)}
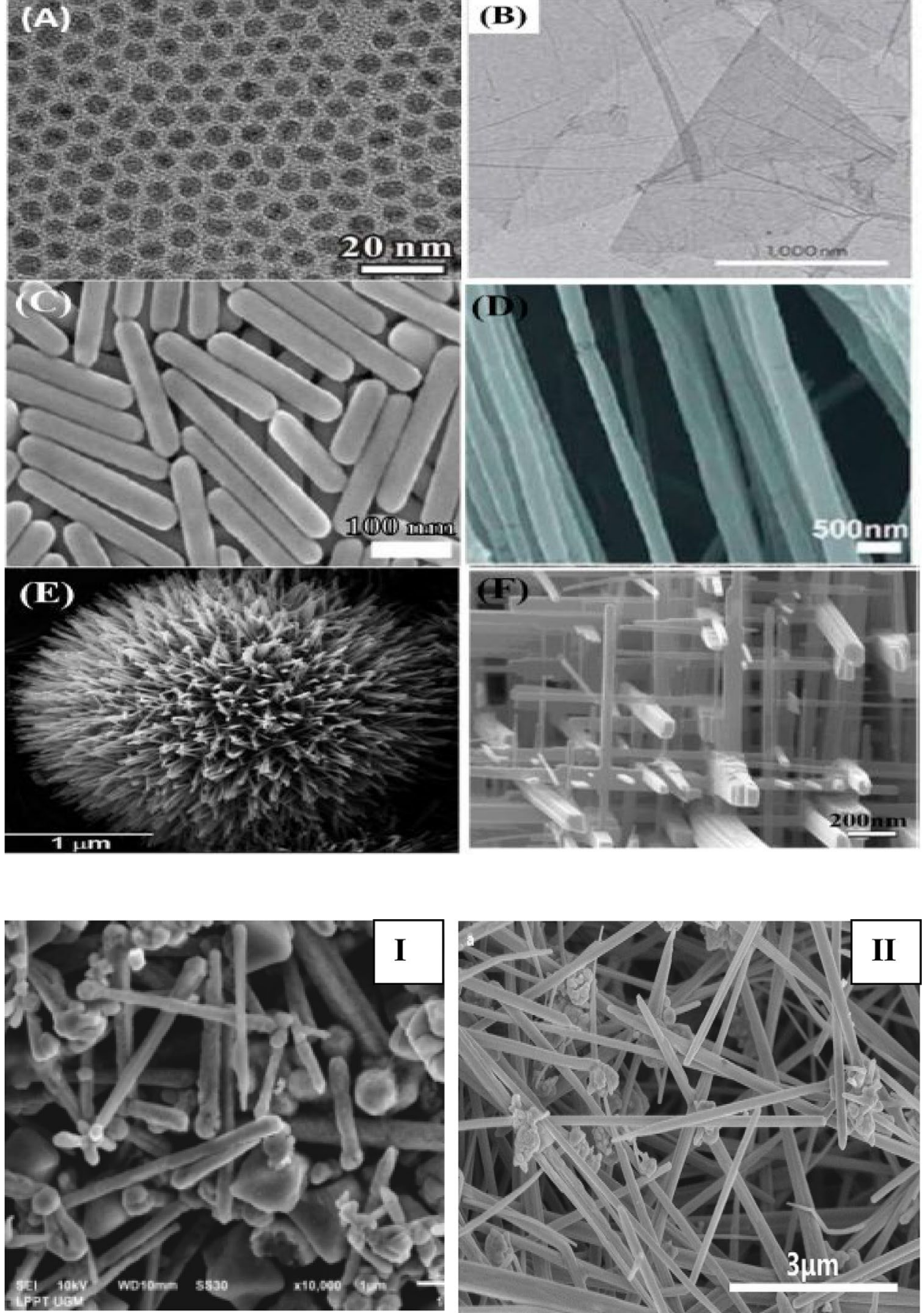

Fig. 3 SEM image of $\mathrm{Cu}$ nanorods (I) [12], Cu nanowires (II) [13] atmosphere, lithosphere and even in the biosphere), regardless of human actions $[24,25]$.

1.4.3.2 Synthetic (engineered) nanomaterials They are produced by mechanical grinding, engine exhaust, and smoke, or are synthesized by physical, chemical, biological or hybrid methods [26].

\subsection{Approaches of nanomaterials}

Nanomaterials can be synthesized via two main approaches.

\subsubsection{Top-down approach}

It starts with a material of interest, which then undergoes size reduction of physical and chemical processes to produce tiny particles as nanoparticles. 
Fig. 4 HRTEM image $\mathrm{Cu}$ nanocubes (I) and TEM image of triangular Cu nanosheets (II) [14]
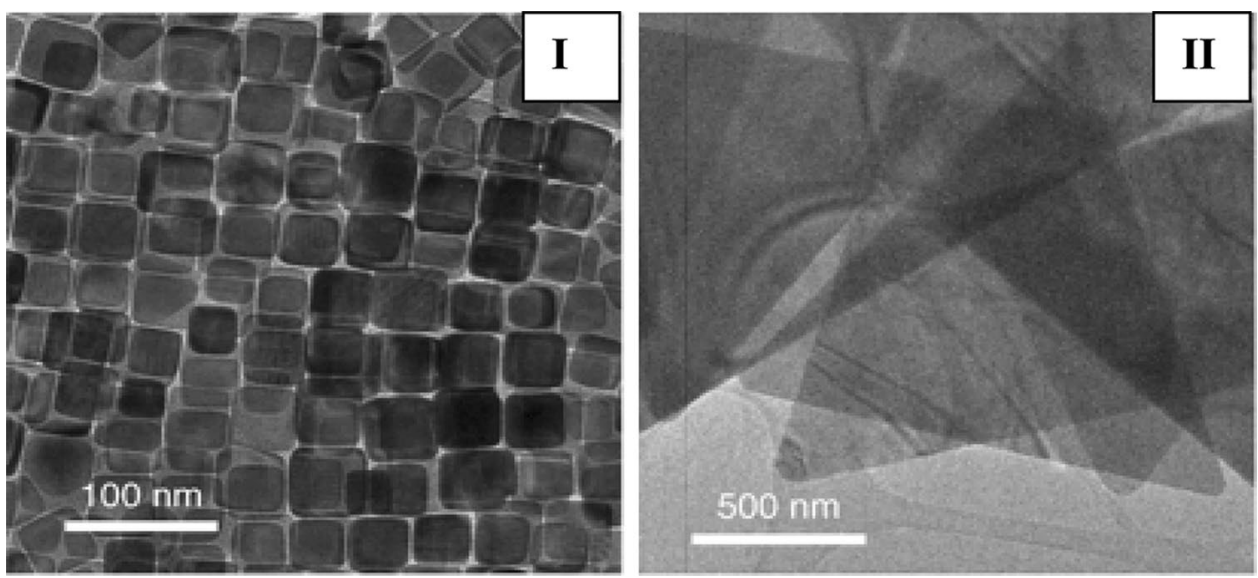

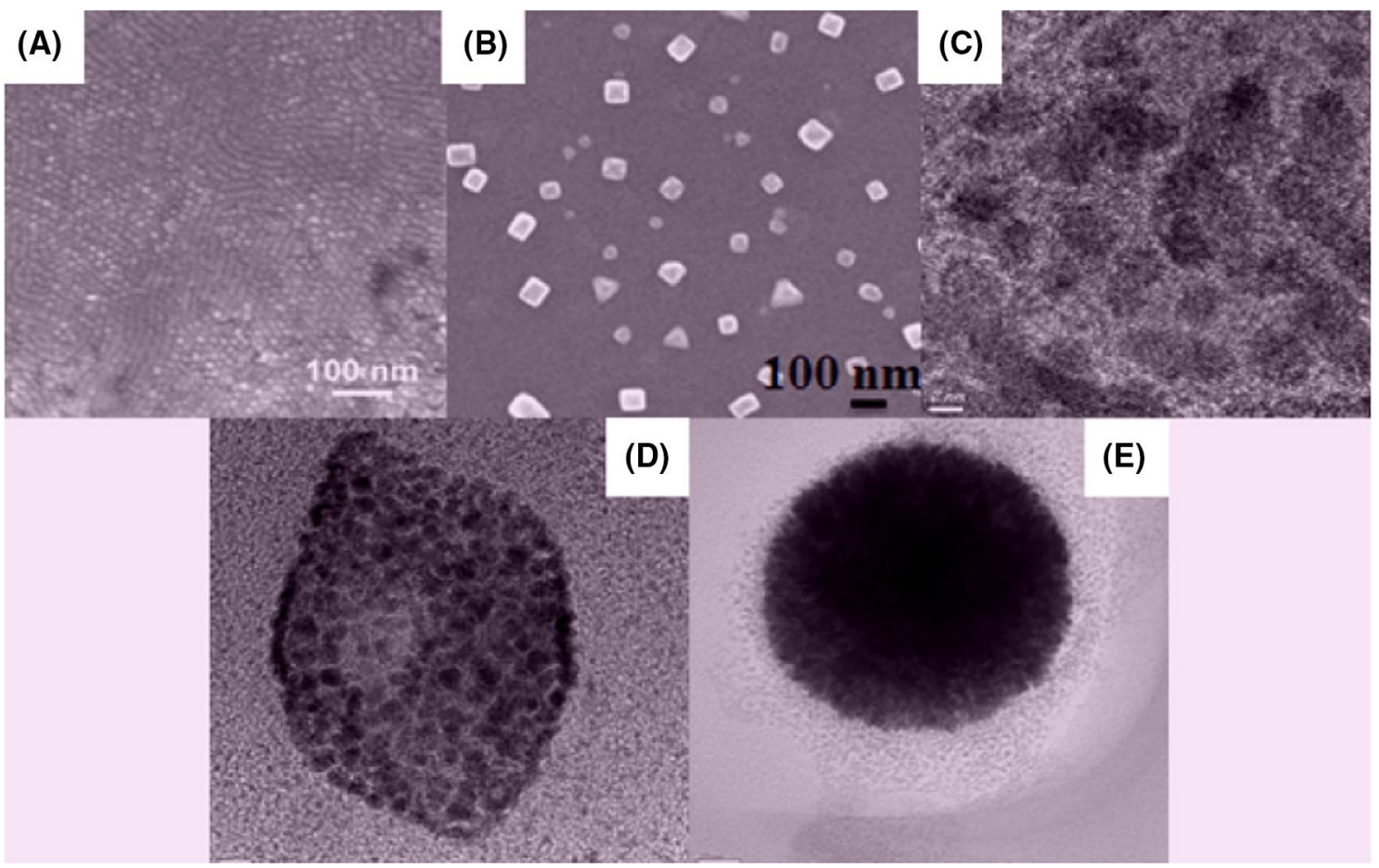

Fig. 5 Typical scanning electron microscope (SEM) and transmission electron microscope (TEM) image of different types of $O D$ NSMs, which is synthesized by several research groups. a Quantum

\subsubsection{Bottom-up approach}

Nanoparticles are built from atoms, molecules, and smaller particles/monomers. This approach is more favorable because it offers greater ability in control of the size, shape, and morphology for the resulting nanoparticles, Table 1 and Fig. 6 summarize different synthesis methods of NPs.

\subsubsection{Green biosynthesis of NPs by botanical} extracts Green chemistry is an implementation, devel- dots, b nanoparticles arrays, c core-shell nanoparticles, d hollow cubes and e nanospheres [23]

opment, design of chemical products and processes to minimize the use of hazardous to the environment. Green synthesis method was found to be the best method when compared to the other method such as chemical reduction [27], photochemical reduction [28], electrochemical reduction [29], thermal decomposition [30], etc. Green method has several advantages over other methods such as cost-effectiveness, simplicity, use of less temperature and the usage of less toxic materials. Moreover, it is compatible with medical and food applications. Many 
Table 1 Some important manufacturing methods used in nanoparticle synthesis

\begin{tabular}{ll}
\hline Synthesis of nanoparticles & \\
\hline Top-down approaches & Bottom-up approaches \\
\hline Laser ablation (Thermal) & Laser pyrolysis \\
Etching & Sol \& Sol-Gel \\
Sputtering (kinetic) & Aerosol based process \\
Mechanical milling & Plasma or flame spraying \\
Electro-explosion & Atomic or molecular condensation \\
(Thermochemical) & Chemical vapor deposition \\
& Supercritical fluid \\
& Spinning \\
& Green synthesis \\
& Biological methods \\
& Actinomycetes \\
& Algae \\
& Bacteria \\
Yeasts \\
Fungi \\
Plants
\end{tabular}

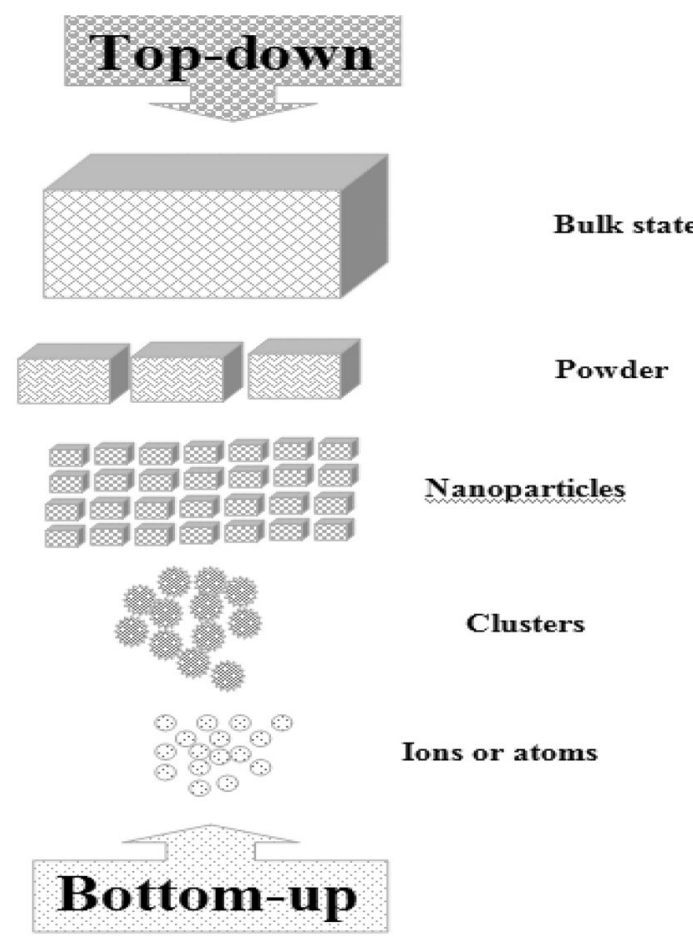

Fig. 6 The scheme represents top-down and bottom-up approaches

researchers used green synthesis methods for different metal nanoparticles due to their growing need for ecofriendly properties [31-33].
Plants have been considered a more environmentfriendly route for biologically synthesizing metallic nanoparticles and for detoxification applications. Plant extracts containing bio-active [34] flavonoids as alkaloids, phenolic acids, polyphenols [35], proteins [36, 37], sugars [38], and terpenoids are believed to have an important role in first reducing the metallic ions and then stabilizing them. The variation in composition and concentration of these active biomolecules between different plants and their subsequent interaction with aqueous metal ions is believed to be the main contributing factor to the diversity of nanoparticle sizes and shapes produced [39, 40]. Importantly, the synthesis of nanoparticles from reducing metal salts via plants is relatively simple at room temperature process. The process begins by mixing a sample of a plant extract with a metal salt solution. Biochemical reduction of the salts starts immediately and the formation of nanoparticles is indicated by a change in the color of the reaction mixture. During synthesis, there is an initial activation period when process metal ions are converted from their mono or divalent oxidation states to zero-valent states and nucleation of the reduced metal atoms takes place [41]. This is immediately followed by a period of growth when smaller neighboring particles amalgamate to form larger nanoparticles that are thermodynamically more stable while further biological reduction of metal ions takes place. As growth progresses nanoparticles aggregate to form a variety of morphologies such as cubes, spheres, triangles, hexagons, pentagons, rods, wires and etc. In the final stage of synthesis, the plant extracts the ability to stabilize the nanoparticle ultimately determines it's most energetically favorable and stable morphology [40].

\section{Role of flavonoids and polyphenols in plant extracts} as reducing, capping and stabilizing agents Flavonoids are a large group of polyphenolic compounds that contain several classes: isoflavonoids, flavonols, chalcones, flavones, and flavanones, which can actively chelate and reduce metal ions into nanoparticles. Flavonoids contain various functional groups capable of nanoparticle formation "as a reducing agent". Transformations of flavonoids from the enol-form to the keto-form may release a reactive hydrogen atom that can reduce metal ions to form nanoparticles. Some flavonoids are able to chelate metal ions with their carbonyl groups or $\pi$-electrons. For example, quercetin, luteolin, tryptophan as in Fig. 7, is a flavonoid which is a very strong chelating ligand. It can chelate metals through three positions; the carbonyl and hydroxyls positions and also the catechol. These groups chelate various metal ions such as $\mathrm{Fe}^{+2}, \mathrm{Fe}^{+3}, \mathrm{Cu}^{+2}, \mathrm{Zn}^{+2}$, $\mathrm{Al}^{+3}, \mathrm{Cr}^{+3}, \mathrm{~Pb}^{+2}$, and $\mathrm{Co}^{+2}[35,38]$. Capping agents used for stabilization of the nanoparticles in the colloidal synthesis, controlling in particle morphology and protect the surface 
Fig.7 Quercetin (a), luteolin (b), tryptophan (c)<smiles>O=c1c(O)c(-c2ccc(O)c(O)c2)oc2cc(O)cc(O)c12</smiles>

(A)<smiles>O=c1cc(-c2ccc(O)c(O)c2)oc2cc(O)cc(O)c12</smiles>

(B)<smiles>N[C@@H](Cc1c[nH]c2ccccc12)C(=O)O</smiles>

(C)

from aggregation [42]. Many plant species are reported in nanoparticles synthesis are such as leaf extracts [43], essential oils [44], peel extracts, gum extracts [45], seed extracts [46], tissue culture extracts [47], seedling extracts $[35,48,49]$, whole-plant extracts [50], etc.

\section{Advantages of using plants over bacteria and fungi Uti-} lization of plants has many advantages such as no need for culture preparation and isolation maintenance, inexpensive, environmentally friendly, stable, safe and non-toxic, short production times and easily scaled up for large-scale production of nanoparticles [51, 52].

\subsection{Properties of nanoparticles/nanomaterials}

For the last two decades, the NMs have drawn significant attention due to their unique properties, such as conductive, catalytic, magnetic, optical and mechanical properties. It is well-known that the NMs are of larger surface area per weight (also called ultrahigh surface effect), high affinity towards a certain group of elements or compounds (can be explained by high volume effect), and lower conduction than the original metallic materials (can be explained by the electron confinement) [53].

\subsubsection{Optical properties}

The NMs can emit a photon when the sunlight hits the surface of these materials. When the particle size decreased to the nanoscale, the wavelength of NMs is on the same order of the visible light. Therefore, light can be scattered by the NMs (known as the Tyndall effect) [54]. The ultrafine particles tend to move randomly (commonly known as Brownian motion).

\subsubsection{Conductive properties}

In general, nanomaterials contained transition metals displayed lower conduction compared to their original bulk substances [53]. The transition metals nanoparticles are an important class in the Semiconductors industry, which have expressed significant advances owing to a wide range of applications in the field of sensors, electronics, and chips [55]. Green route synthesis using plant extract supplies stability for the formed nanoparticles with surrounding the particles by some of the adsorbed species present in the extract. This is caused by the higher band gap of the nanoparticles comparing with its bulk state moreover, its particle size at nanoscale.

\subsubsection{Catalytic properties}

The NMs showed high catalytical reactivities due to the high surface to volume ratio. Due to the presence of a large number of unbonded atoms, the NMs are highly reactive $[44,56,57]$. 


\subsubsection{Magnetic properties}

If NMs have one or more unpaired electrons, the NMs exhibit para magnetism. Otherwise, the NMs are diamagnetic. Below a critical temperature, the ferromagnetic can become superparamagnetic due to the quantum size effect. In general, the manganic properties affected the particle size of NMs [58-60].

\subsubsection{Mechanical properties}

The NMs normally have higher tensile strength than the original bulk materials. The higher surface tension, resulting from the dangling atoms within the NMs, will allow for a solid connection between different particle clusters. Therefore, nanomaterials can tolerate higher stretching or pulling forces without being damaged [53].

\subsubsection{Adsorptive properties}

Owing to the distinct features of NMs such as small particle size, catalytic potential, large surface area and a great number of active sites for the interaction with different pollutants, the NMs considered a highly promising class of adsorbents for removal of pollutants [61-65].

\section{Copper nanoparticles literature survey}

\subsection{Background}

Copper $(\mathrm{Cu})$ is a transition metal with a distinct red-orange color and metallic luster having atomic number 29 and atomic mass 63.546. It is relatively more abundant metallic element of the Earth's crust (the 8th), hence cheaper material to use. Copper has special properties [66] of high electrical conductivity, high thermal conductivity, high corrosion resistance, good ductility and malleability, and its reasonable tensile strength make it an essential element in the functioning of society and has played several important roles in society for thousands of years. These properties have made copper the number one of materials used in modern household water piping and associated plumbing and the metal of choice for most vehicle radiators and air conditioners. Copper has been used as a biocide for centuries [67]. Copper is one of a relatively small group of metallic elements that are essential to human health as it is a constituent of many enzymes involved in numerous body functions and is a constituent of hair and of elastic tissue contained in the skin, bone and other body organs [68]. A number of recent studies have explored the potential benefit of using copper in place of stainless steel on surfaces to reduce bacterial loads in a number of settings including hospitals and the food industry $[69,70]$.

Cu NPs, due to their high surface to volume ratio is very reactive; they can easily interact with other particles and increase their antimicrobial efficiency [71, 72].

Although copper is one of the most widely used materials in various applications, its synthesis in nano sizes is challenging due to its high tendency for oxidation. Unlike gold and silver, copper is extremely sensitive to air, and the oxide phases are thermodynamically more stable [73]. The presence of copper oxides on the surface of nanoparticles is not desirable for many industries, such as electronics that count on copper as a good alternative for current expensive metals. The electrical conductivity of copper nanoparticles (Cu NPs) decreases dramatically if they become impure with oxide phases $[74,75]$. One can rarely find a method in the literature that produces pure Cu NPs unless the whole procedure was done under an inert atmosphere [76].

\subsection{Copper nanoparticles synthesis methods}

Khanna [77] described his achievement in the synthesis of pure Cu NPs by reducing copper salt in the presence of surfactant. Cu NPs can easily oxidize to form copper oxide. If the application requires the Cu NPs to be protected from oxidation, the $\mathrm{Cu}$ NPs are usually encapsulated in organic using capping and a stabilizing agent or inorganic materials such as carbon and silica [78].

Reported methods for the preparation of Cu nanoparticles, includes: thermal reduction [79], metal vapor synthesis [80], radiation method [81], microemulsion technique [82], laser ablation [83], mechanical attrition [84], chemical reduction [85] and biological synthesis $[86,87]$ and green approaches [88].

\subsubsection{Biosynthesis of Cu NPs using different plant extracts}

Valodkar et al. $[89,90]$ prepared peptide capped copper nanoparticles using stem latex of Euphorbia nivulia "common milk hedge" as reducing and capping agent. Valodkar and his coworkers studied the biological effect on tumor cells [89] and the antimicrobial applications [90] of prepared Cu NPs. In the same year, a study conducted by Lee et al. [91] to get Cu NPs by using of Magnolia kobus leaf extract. In 2012, Cu NPs were synthesized using aqueous Calotropis procera latex extract [92] and their cytotoxicity on tumor cells has been studied. In 2013 Subhankari and Nayak investigated Ginger "Zingiber officinale" [93] and Syzygium aromaticum "Clove" [94] extracts and they studied the antimicrobial activity of formed NPs. Capparis zeylanica [95], Vitis vinifera [96], Nerium oleander leaf [97]. 
leaf extracts were also explored to synthesize Cu NPs in 2014 and their antibacterial action has been investigated. Various plant extracts have been explored in 2015; Pineapple [98], Citrus grandis peel [99], Hibicus Rosasinensis leaf [100], Guava [101], Phyllanthus embilica "Gooseberry" [34], Ginkgo biloba L. leaf [57] Lemon fruit [102] and Aloe vera flower [103]. The formed Cu NPs have been tested to assess their catalytic [57, 99], antioxidant [100] and antimicrobial [34, 100-102] activities.

Moreover, Tridax procumbens leaves [104], Arevalanata leaves [105], Datura innoxia aqueous leaves [106], Punica granatum peel [107], Cassia Auriculata leaf [108] and Allium Sativum "chopped garlic leaves" [109] were used as reducing and capping agents to bio-synthesize Cu NPs in 2016. The catalytic [104] and microbial [105-109] activities of green synthesized NPs have been studied.

Nasrollahzadeh et al. [110] utilized Plantago asiatica leaf to get $\mathrm{Cu}$ NPs and their application for the cyanation of aldehydes using $\mathrm{K}_{4} \mathrm{Fe}(\mathrm{CN})_{6}$ have been performed. In another study, Triumfettarotundifolia [111] extract mediated synthesis of Cu NPs and its pharmacological activities have been carried out.

Recently, Tilia extract was used for the first time in the biosynthesis of Cu NPs with satisfying results as reported [112], Padma et al. [113] investigated Punica granatum fruit rind extract to green synthesize Cu NPs in 2018. In another work conducted by Rajesh [114], the extract of Syzygium aromaticum bud has been used. The physical, optical and antimicrobial properties of the formed NPs have been evaluated. In the same year, 2018, Azadirachta indica leaf extract was utilized by Nagar and Devra [115].

In 2019, zerovalent Cu NPs were synthesized by using Ripened Duranta erecta fruit [116] extract to reduce toxic azo dyes congo red and methyl orange from water. The flower, leaf, and stem of Gnidia glauca and Plumbago zeylanica [117] extract is used to get Cu NPs which applied as an antidiabetic agent. Tinosporia cardifolia [118] extract was also reported in 2019 to produce nature-friendly copper nano-coated fabric and their antimicrobial activities have been evaluated by Sharma et al. Summary of biosynthesis of $\mathrm{Cu}$ NPs using different plant extracts was tabulated in Table 2.

\subsection{Optical properties of Cu NPs}

The dispersion of metal nanoparticles displays intense colors due to the surface plasmon resonance (SPR) absorption. The surface of metals like Cu can be treated as freeelectron systems called plasma, containing equal numbers of positive ions (fixed in position) and conduction electrons (free and highly mobile). Under the irradiation of an electromagnetic wave, the free electrons are driven by the electric field to oscillate coherently at a plasma frequency relative to positive ions [119]. The metals rich in free electrons revealed this property so, it mostly used as a plasmonic material [120]. A number of metals (i.e., Li, $\mathrm{Na}, \mathrm{Al}, \mathrm{In}, \mathrm{Ga}$, and $\mathrm{Cu}$ ) are supporting SPR for at least part of the UV-Vis-NIR region. These free electrons provide the negative real permittivity that is an essential property of any plasmonic material [121]. However, metals are suffering from large losses, especially in the Uv-Vis. spectral ranges, arising in part from inter-band electronic transitions. Even the metals with the highest conductivities suffer from large losses at optical frequencies $[122,123]$. However, most of these metals are either unstable, difficult to work with, or subjected to surface oxidation that can significantly affect the optical properties. Such a phenomenon is responsible for optical properties for formed NPs. The SPR peak strongly affected by the synthesized particle size, capping agent, shape, solvent type and reaction $\mathrm{pH}$ which can be driven to give the best result with modification of the $\mathrm{pH}$ value to 8-12 [85]. Solvents rich by $\pi$ bonds decrease from the actual Cu NPs SPR intensity at least 3 times compared with solvents that have not contained $\pi$ bonds as the result of the sharing of $\pi$ bonds with $\mathrm{Cu}$ surface. Briefly, the solvent molecules contain delocalized $\pi$-bond electrons can improve Cu NPs electron density surface and reduce the density of free electrons in the conduction band with a reduction of the plasmon oscillations, also the tendency of Cu NPs for oxidation is rapid [124]. As a result of surface oxidation, the surface plasmonic properties of $\mathrm{Cu}$ have not received much attention as compared to $\mathrm{Ag}$ and $\mathrm{Au}$ [125]. Furthermore, copper is plagued by large inter-band losses over most of the visible spectrum. Inter-band transitions, which form a significant loss mechanism in materials at optical frequencies, occur when electrons jump to higher, empty energy levels caused by absorption of incident photons. In metals, when a bound electron absorbs an incident photon, the electron can shift from a lower energy level to the Fermi surface or from near the Fermi surface to the next higher empty energy level. Both of these processes result in a high loss at optical frequencies [121]. In semiconductors, valence electrons absorbing the energy from a photon and shifted into the conduction band, resulting in loss. This loss appeared as an increase in the imaginary part of the dielectric constant.

\subsubsection{UV-visible data and particle size of copper nanoparticles}

Several bio-synthesized methods revealed surface plasmon resonance absorption for $\mathrm{Cu}$ NPs which is a unique property. The common absorption peaks of Cu NPs located in the visible light range of $530-590 \mathrm{~nm}$. It was believed that the variety of the absorption peaks is a result of the difference of bio-active molecules which responsible 
Table 2 Different plants used in the biosynthesis of Cu NPs

\begin{tabular}{|c|c|c|c|c|}
\hline Copper Salt & Plant & Particle size $(\mathrm{nm})$ & Shape & References \\
\hline Copper chloride & Ginkgo biloba L. leaf & $15-20$ & Spherical & {$[57]$} \\
\hline Copper sulfate & Pineapple & $30-50$ & Cubic & [98] \\
\hline Copper sulfate pentahydrate & Citrus grandis peel & $22-27$ & Spherical & [99] \\
\hline Copper nitrate & Hibicus Rosasinensis leaf & 500 & Spherical & {$[100]$} \\
\hline Copper nitrate & Euphorbia nivulia stem latex & $5-10$ & Spherical & {$[89,90]$} \\
\hline Copper sulfate pentahydrate & Magnolia kobus leaf & $45-110$ & Spherical & {$[91]$} \\
\hline Copper acetate & Calotropis procera latex & $15 \pm 1.7$ & Spherical & {$[92]$} \\
\hline Copper sulfate & Ginger "Zingiber officinale" & $25-40$ & - & {$[93]$} \\
\hline Copper sulfate & Syzygium aromaticum "Clove" & $5-40$ & Spherical \& granular & [94] \\
\hline Copper sulfate & Zeylanica & $50-100$ & Cubic & {$[95]$} \\
\hline Copper sulfate & Vitis vinifera & - & - & {$[96]$} \\
\hline Copper sulfate & Nerium oleander leaf & - & - & {$[97]$} \\
\hline Copper sulfate & Guava & $15-30$ & Flakes & [101] \\
\hline Copper sulfate & Phyllanthus embilica "Gooseberry" & $15-30$ & Flake & [34] \\
\hline Copper chloride & Lemon fruit & 45 & Cubic \& rod & {$[102]$} \\
\hline Copper acetate & Aloe vera flower & 40 & Spherical & {$[103]$} \\
\hline Copper acetate & Tridax procumbens leaves & 87 & Spherical & [104] \\
\hline Copper sulfate & Arevalanata leaves & $40-100$ & Spherical & [105] \\
\hline Copper sulfate & Datura innoxia aqueous leaves & $5-15$ & Spherical & {$[106]$} \\
\hline Copper sulfate pentahydrate & Punica granatum peel & $15-20$ & Spherical & [107] \\
\hline Copper sulfate & Cassia Auriculata leaf & $38.1-43.5$ & Spherical & {$[108]$} \\
\hline Copper sulfate & Allium Sativum "chopped garlic leaves" & $83-130$ & spherical & [109] \\
\hline Copper chloride & Plantago asiatica leaf & $7-35$ & Spherical & [110] \\
\hline Copper sulfate pentahydrate & Triumfettarotundifolia & 12.46 & $\begin{array}{l}\text { Like } \\
\text { triangle }\end{array}$ & {$[111]$} \\
\hline Copper sulfate pentahydrate & Tilia extract & 27.6 & Spherical & [112] \\
\hline Copper sulfate & Punica granatum fruit rind & $56-59$ & Spherical & [113] \\
\hline Cupric acetate & Syzygium aromaticum bud & 12 & Spherical & [114] \\
\hline Cupric chloride & Azadirachta indica leaf & 48 & Cubic & {$[115]$} \\
\hline Copper sulfate pentahydrate & Ripened Duranta erecta fruit & 76 & Spherical & [116] \\
\hline Copper sulfate pentahydrate & $\begin{array}{l}\text { Flower, leaf, and stem of Gnidia glauca and } \\
\text { Plumbago zeylanica }\end{array}$ & $1-5$ & Spherical & [117] \\
\hline Copper chloride & Tinosporia cardifolia & 63.3 & Spherical & {$[118]$} \\
\hline
\end{tabular}

for the reduction process for copper precursors. So, the particle size varies according to the applied preparation method and the nature of the plant. This was described in various green synthesis methods as reported. Lee et al. [91] reported the Cu NPs absorption peak at $560 \mathrm{~nm}$ with the particle size range 45-110 $\mathrm{nm}$. Harne et al. [92] found the same characterestic absorption peak at $570 \mathrm{~nm}$. The particle size was $20 \mathrm{~nm}$ as conducted by XRD and $15 \mathrm{~nm}$ as provided by TEM images. Subhankari and Nayak [94] recorded $570 \mathrm{~nm}$ for the $\mathrm{Cu}$ colloids and 25-40 nm for the average particle size by XRD. Saranyaadevi et al. [95] recorded the $\mathrm{Cu}$ NPs absorption peak at $531 \mathrm{~nm}$ and TEM analysis demonstrated particle size 50-100 nm, while XRD showed average particle size $5 \mathrm{~nm}$. Caroling et al. [34], recorded $576 \mathrm{~nm}$ for the absorption peak and the SEM results displayed average size in the range of $30-50 \mathrm{~nm}$, while Nasrollahzadeh and Sajadi [57] reported 560-580 $\mathrm{nm}$ for the peak and TEM showed the size range 15-20 $\mathrm{nm}$. In another study [102], Cu particles with a maximum absorption peak at $585 \mathrm{~nm}$ revealed sizes in the $60-100 \mathrm{~nm}$ range by TEM results while XRD showed that the average size is $45 \mathrm{~nm}$. Karimi and Mohsenzadeh, reported the Cu absorption peak at $578 \mathrm{~nm}$ with $40 \mathrm{~nm}$ average particle size by FESEM. Kaur et al. [107] reported $585 \mathrm{~nm}$ for the peak and particle size 15-20 nm by TEM. Rajesh et al. Cu NPs biosynthesized using Tilia extract showed its surface plasmon peak at $563 \mathrm{~nm}$ in the visible range. In XRD analysis the $\mathrm{Cu}$ NPs average particle size found to be $27.6 \mathrm{~nm}$ while it revealed 4.7-17.4 nm in TEM [112]. Using Syzygium aromaticum bud [114] recorded $580 \mathrm{~nm}$ for the Cu peak with 
particle size $12 \mathrm{~nm}$ by Scherrer formula. The maximum absorption peak was $560 \mathrm{~nm}$, with XRD average particle size $48 \mathrm{~nm}$ as reported by Nagar and Devra [115]. Ismail et al. [116] recorded the characteristic absorption peak of Cu colloids at $588 \mathrm{~nm}$ with XRD average crystallite size $76 \mathrm{~nm}$. Summary of UV-Visible data and particle size of copper nanoparticles tabulated in Table 3.

\subsubsection{Band gap energy of copper nanoparticles}

Semiconductor nanomaterials have been a rapidly growing area of research for the scientific community due to their unique electrical, optical, photonic and mechanical properties. Some of these properties are connected to the surface area to volume ratio of the nanomaterials, which play an important role to characterize their properties. One of the leading and important properties of semiconductors is their band gap. Band gaps play a fundamental role in the electrical and optical properties of semiconductor materials. Singh et al. [126] reported in their studies that the band gap energy increases with the decreasing particle size.

In metals, the conduction bands split into discrete electronic levels, the spacing between these levels and the band gap increasing with decreasing particle size. In the case of semiconductors, the phenomenon is slightly different, since a band gap already exists in the bulk state. However, this band gap also increases when the particle size is decreased and the energy bands gradually convert into discrete molecular electronic levels [127, 128].

The nanoparticles of transition metals are an important class of Semiconductors [55]. In green synthesis using plant extract, the later supplies stability for nanoparticles with some functional groups capping formation. Among various metal nanoparticles, Cu NPs is an important semiconductor $[55,129]$. Cu NPs band gap was reported as $2.1 \mathrm{eV}$ [112], 1.98-2.02 eV [130], $2.1 \mathrm{eV}$ [129], $2.14 \mathrm{eV}$ [131] and $2.3 \mathrm{eV}$ [132]. This range of band gap energy of Cu NPs was attributed to variety in synthetic methods and particle size as a root cause. Summary of bandgap energy of copper nanoparticles tabulated in Table 4.

It's clear for man that is the solids can be divided into three categories according to their conductivity and subsequently, according to the band gap. Conductors either have a conduction band only partly filled with electrons or overlapping conduction and valence bands, $\mathrm{E}_{\mathrm{g}}=$ zero as revealed in Fig. 8. If the conduction band partly contains electrons, the electrons can move within the solid, therefore allowing electrons to be conducted. The specific electrical resistance of conductors is very low at $\rho<10^{-5} \Omega \mathrm{m}$ and so, high electrical conductivity [133]. Isolators, their

Table 3 Different plants used in Cu NPs biosynthesis against its UV-Visible wavelength data

\begin{tabular}{|c|c|c|c|c|c|}
\hline Copper salt & Plant & Particle size $(\mathrm{nm})$ & Shape & Wavelength $(\mathrm{nm})$ & References \\
\hline Copper chloride & Ginkgo biloba L. leaf & $15-20$ & Spherical & $560-580$ & {$[57]$} \\
\hline Copper sulfate pentahydrate & Magnolia kobus leaf & $45-110$ & Spherical & 560 & [91] \\
\hline Copper acetate & Calotropis procera latex & $15 \pm 1.7$ & Spherical & 570 & {$[92]$} \\
\hline Copper sulfate & Syzygium aromaticum "Clove" & $5-40$ & Spherical \& granular & 570 & [94] \\
\hline Copper sulfate & Zeylanica & $50-100$ & Cubic & 531 & {$[95]$} \\
\hline Copper sulfate & Phyllanthus embilica "Gooseberry" & $15-30$ & Flake & 576 & {$[34]$} \\
\hline Copper chloride & Lemon fruit & 45 & Cubic \& rod & 585 & [102] \\
\hline Copper sulfate pentahydrate & Punica granatum peel & $15-20$ & Spherical & 585 & [107] \\
\hline Copper sulfate pentahydrate & Tilia extract & 27.6 & Spherical & 563 & [112] \\
\hline Cupric acetate & Syzygium aromaticum bud & 12 & Spherical & 580 & [114] \\
\hline Cupric chloride & Azadirachta indica leaf & 48 & Cubic & 560 & [115] \\
\hline Copper sulfate pentahydrate & Ripened Duranta erecta fruit & 76 & Spherical & 588 & [116] \\
\hline
\end{tabular}

Table 4 Different synthesized Cu NPs against its band gap energy

\begin{tabular}{llllll}
\hline Copper salt & Plant/chemical & Particle size $(\mathrm{nm})$ & Shape & Eg (eV) & References \\
\hline Copper sulfate pentahydrate & Tilia extract & 27.6 & Spherical & 2.1 & {$[112]$} \\
Copper sulfate & Tea leaf extract & $70-90$ & Spherical & $1.98-2.02$ & {$[130]$} \\
Copper sulfate pentahydrate & Gelatin & - & - & 2.14 & {$[131]$} \\
Copper sulfate & $\begin{array}{c}\text { Sodium borohydride and } \\
\text { tri-sodium citrate }\end{array}$ & 22 & Spherical & 2.3 & {$[132]$}
\end{tabular}




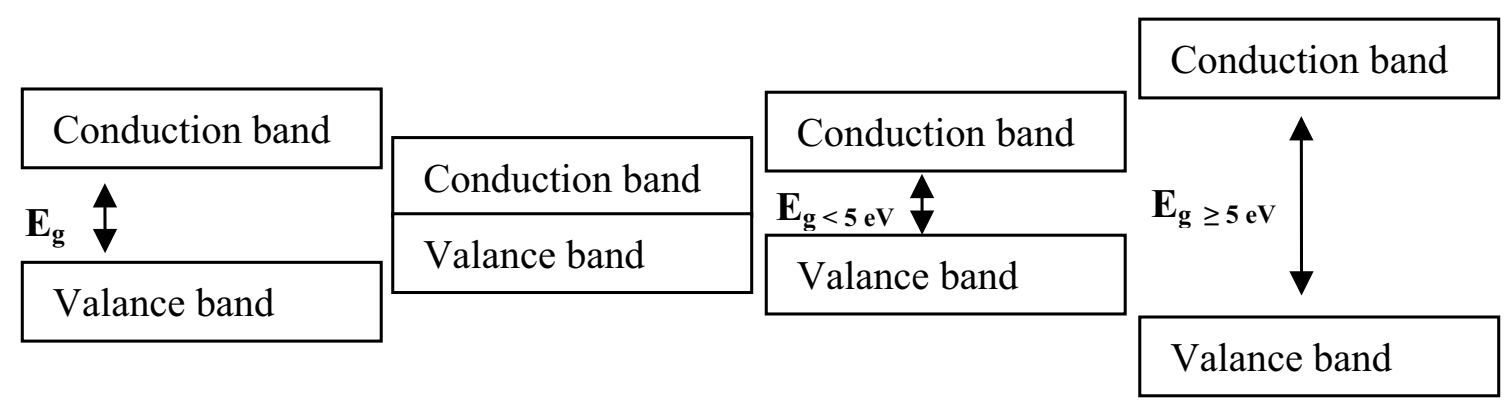

\section{Conductors}

Fig. 8 Conductors, semiconductors, and isolators energy gap diagram

\section{Semiconductors}

Isolators conduction band has no electrons and the great band gap $\mathrm{E}_{\mathrm{g}} \geq 5 \mathrm{eV}$. Semiconductors are crucial. Their conductivity ranges from $10^{-5}$ to $10^{7} \Omega \mathrm{m}$. Like isolators, their conductance band has no electrons, but the relatively small band energy, $\mathrm{E}_{\mathrm{g}}<5 \mathrm{eV}$ means that solar energy can move electrons into the conduction band. When photons move electrons into the conduction band, we speak of the internal photoelectric effect. If the photon's energy is smaller than the band gap, the electron cannot get through to the conduction band. If the photon's energy is too great, the electron does enter the conduction band, but part of the energy is lost because the electron falls back to the edge of the conduction band [133]. If the energy of the light is greater than or equal to the energy of the conduction band minus the energy of the valence band, $E_{\text {light }} \geq E_{c}-E_{v}$, then electrons can be photo-excited from the valence into the conduction band [134].

Semiconductor "nanoparticles" exhibit a bandgap that depends on the particle diameter; the smaller the nanoparticle, the larger the bandgap [135].

\subsubsection{Photoluminescence (PL) of copper nanoparticles}

Photoluminescence is an important tool for measuring the purity and crystallinity quality of semiconductors and quantification of the amount of disordering present in the crystal lattice system. Photoluminescence has a wide range of applications as band gap determination, impurity level and defects detections, recombination mechanism interpretation, material quality check, molecular structure and crystallinity modeling.

Mooradian [136] observed the photoluminescence of copper and extensively used it in explaining the band structure of metals [137]. This emission is attributed to the direct radiative recombination of the excited electrons in the $s p$ band with the holes in the $d$ band [137].

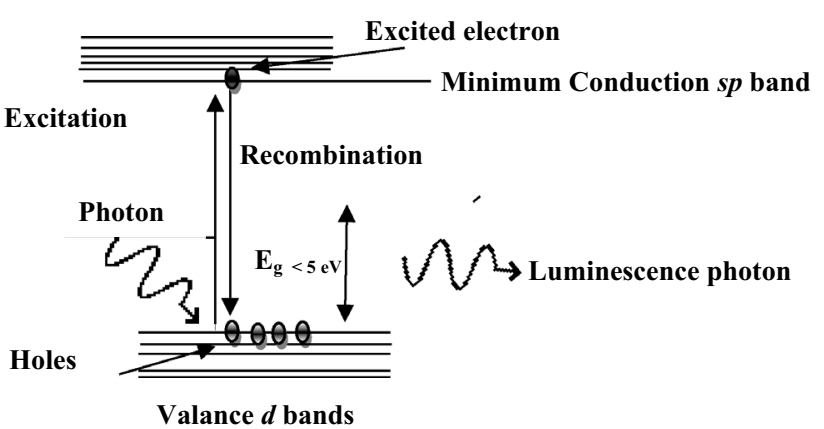

Fig. 9 Photoluminescence diagram

Usually, the visible photoluminescence from metal nanoparticles is due to the inter-band transition between the $s p$ conduction bands and the $d$ bands as shown in Fig. 9 . The electronic structure of a copper atom can explain the photoluminescence spectra of $\mathrm{Cu}$ nanoparticles. In the case of copper, $3 d$ valence and $4 s p$ conduction electrons play the main role in the fluorescence phenomenon. The outermost $d$ and $s$ electrons of all the constituent atoms of the nanoparticles create six bands. Five of these bands lie below the Fermi level, which is denoted as $d$ bands and the sixth band, the last band, which lies above the Fermi level, is known as the conduction band or sp band [138].

Metals can be excited by a low-intensity source in the UV region of spectra. Soskovets et al. [139] reported that the luminescence of planar nanostructures based on amorphous copper by a low-intensity source in the UV spectrum. In Cu NPs capped by linoleic acid, excitation at $350 \mathrm{~nm}$ from Xenon laser leads to the excitation of $d$-band electrons into the sp-conduction band due to inter-band transition. Radiative recombination of electron-hole pair between $d$-band and sp-conduction band followed by initial electronic relaxation produces luminescence, which practically occurs at $530 \mathrm{~nm}$. Adsorbed linoleic acid on 
the surface of Cu NPs can enhance the emission peak. But the emission peak observed here for Cu NPs is due to the inter-band transition, which has been explained [139].

The photoluminescence spectrum of Cu-NPs [112] revealed an exciting peak at $562 \mathrm{~nm}$ at excitation $435 \mathrm{~nm}$. Fluorescence peak was obtained at $530 \mathrm{~nm}$ when excited with $350 \mathrm{~nm}$ of an optical source [139]. Excitation wavelengths for Cu NPs were set at $340 \mathrm{~nm}$ and $480 \mathrm{~nm}$, and the emission spectra from 515 to $645 \mathrm{~nm}$ and from 500 to $600 \mathrm{~nm}$ were collected respectively [140]. The photoluminescence emission was $625 \mathrm{~nm}$ when Cu NPs exited at $524 \mathrm{~nm}$ as reported by Wang et al. [141], also, a strong emission peak was exhibited at $600 \mathrm{~nm}$ when Cu NPs were excited at $344 \mathrm{~nm}$ [142]. Photoluminescence spectra of Cu NPs bio-synthesized using Gum Kondagogu extract showed an emission peak at $430 \mathrm{~nm}$ when illuminated at $325 \mathrm{~nm}$ [143]. Cu NPs PL revealed an emission band in the near-infrared region at $816 \mathrm{~nm}$ with photoexcitation with UV-vis light at $360 \mathrm{~nm}$ [144]. The collected data revealed that the PL emission of Cu NPs not only depends on the excitation wavelength; but also the adsorbed biomolecules on the surface of synthesized Cu NPs, particle size, shape, and the ratio of reducing and capping agent which can enhance the emission peak and also, irradiation time as Gui et al. [145] reported. Summary of photoluminescence of copper nanoparticles tabulated in Table 5.

\subsection{Electrical properties of copper nanoparticles}

In the last 20 years, Cu NPs were used as alternatives for other noble metals in many applications such as heat transfer and inkjet printing. Inkjet printing is the most promising technology that uses noble metals such as gold and silver for printing highly conductive elements [85, 146]. The cost of noble metals is very high when compared with copper. Therefore, copper is mostly preferred for fabricating highly conductive Cu patterns on a plastic substrate by inkjet printing because of its low cost and high conductivity $[124,147]$. The challenge in the use of Cu NPs is rapid oxidation affinity [85]. for its particles in the air. Oxides are not conductive which delimits $\mathrm{Cu}$ usage in printed electronics applications. Cu NPs can be protected to use in the ink formulation by using protecting agents such as ligands $[85,148]$. Cu NPs could be applied as conductive ink for applications such as printed electronics [32]. The green biosynthesized of Cu NPs using Tilia extract revealed an electrical conductivity $\left(1.04 \times 10^{-6} \mathrm{~S} \mathrm{~cm}^{-1}\right)$ at $\mathrm{T}=120^{\circ} \mathrm{C}[112]$.

\subsection{Adsorption properties}

Unfortunately, there are limited sources on using of green synthesized Cu NPs as adsorbent. However, it is reported by Paixão et al. [149] that the green synthesis method for the impregnation of Cu NPs on a carbon surface was effective for nitrate removal from contaminated water. The evaluated process parameters have shown that this modified adsorbent has the potential for use in batch systems, presenting itself as an environmentally favorable alternative to the removal of contaminants from water. The obtained results showed also that the nitrate removal by pure activated carbon was only $16.40 \%$ and the uptake by activated carbon impregnated with Cu NPs was $37.86 \%$.

Oliveira et al. [150], investigated the removal of beta-lactam antibiotics "Cefadroxil and Ceftriaxone" by zerovalent Cu NPs. The study showed excellent removal rates (>85\%) for both antibiotics in only $20 \mathrm{~min}$. These results make the using of Cu NPs is very promising in the decontamination of these compounds in aqueous systems. Mohindru and Garg [130] also recommend in their paper the significance and effectivity of $\mathrm{Cu}$ NPs use in water treatment. Recently, Husein et al. reported the adsorptive efficiency of Cu NPs in the removal of the pharmaceutical pollutants "Diclofenac,
Table 5 Different synthesized Cu NPs against its PL

\begin{tabular}{|c|c|c|c|c|c|}
\hline Copper salt & Plant/chemical & $\begin{array}{l}\text { Particle size } \\
(\mathrm{nm})\end{array}$ & Shape & $\begin{array}{l}\text { Emission/excitation } \\
(\mathrm{nm})\end{array}$ & References \\
\hline $\begin{array}{l}\text { Copper sulfate } \\
\text { pentahydrate }\end{array}$ & Tilia extract & 27.6 & Spherical & $562 / 435$ & [112] \\
\hline Copper chloride & $\begin{array}{l}\text { Sodium linoleate/etha- } \\
\text { nol/linoleic acid }\end{array}$ & $12 \pm 1$ & Spherical & $530 / 350$ & [139] \\
\hline Copper sulfate & Ascorbic acid & - & - & $\begin{array}{l}515-645 / 340 \\
500-600 / 480\end{array}$ & [140] \\
\hline $\begin{array}{l}\text { Copper sulfate } \\
\text { Copper nitrate } \\
\text { Copper chloride } \\
\text { Copper acetate }\end{array}$ & Bovine serum albumin & $2.7 \pm 0.4$ & - & $625 / 524$ & [141] \\
\hline Copper sulfate & Egg white & - & Spherical & $600 / 344$ & [142] \\
\hline Cooper nitrate & Gum Kondagogu & 19 & Spherical & $430 / 325$ & [143] \\
\hline- & Sodium borohydride & $3.2 \pm 0.9$ & & $816 / 360$ & [144] \\
\hline
\end{tabular}


Naproxen and Ibuprofen" from real wastewater samples as a green bio-absorbent by admirable removal efficiency [63].

\subsection{Antimicrobial activity of copper nanoparticles}

Several studies $[34,91,93-98,100-107,109,111-114,118$, $151,152]$ have been conducted that Cu NPs is promising and has high antimicrobial activities either as antibacterial agent for Gram-positive bacteria (Staphylococcus aureus [95-98, 102, 104, 105, 111-113, 152], Bacillus subtilis [96, 97, $100,102,109,112]$ and Bacillus cereus [105]), Gram-negative bacteria (Escherichia coli [34, 91, 93, 95-97, 100-102, 104, 105, 109, 111, 112, 152], Pseudomonas aeruginosa [95, 104, 105, 111, 112], Salmonella typhi [96, 97, 107, 111], Klebsiella pneumonia [96, 97], and Enterobactor [107]), Micrococcus [107], rice pathogen $X$ [106]. oryzae pv. Oryzae [106] or as antifungal agent (Trichoderma viride [98], Aspergillus Niger [98, 102], Candida albicans [102, 111, 112] and Curvularia [102]). Cu NPs activity showed promising results of clear inhibition zone when compared with some of antibiotics (Chloramphenicol [102], Plantomycin [106], Streptomycin [107], Ampicillin [109], Cefepime hydrochloride monohydrate L-arginine [112], Ofloxin [111]) and antifungal drugs (Fluconazole [102, 112] and Ketoconazole [111]).

\subsection{Anticancer activity of Cu NPs}

Based on previous studies, colloidal Cu NPs have been proven to be one of the effective inorganic materials against various cancer cell lines.

As reported by Valodkar et al. $[89,90] \mathrm{Cu} N \mathrm{~N}$ s is toxic to human lung carcinoma cell line (A549) [90], human liver hepatoma (HepG2), Chinese hamster ovary (CHO), human osteosarcoma (Saos), and mouse embryonic fibroblast (3T3L1) cells in a dose-dependent manner [89]. The study revealed that capped Cu NPs by nontoxic aqueous extract of latex can be directly used for administration/in vivo delivery of nanoparticles for cancer therapy [89].

Saranya and Mubarak [151] studied the cytotoxicity effect of Cu NPs on MCF-7 Breast Cancer Cell Lines and they found that the sample with Cu NPs concentration of $10 \mu \mathrm{g} / \mathrm{mL}$ was not sure - enough active. But a significant reduction in the cancer cell; $20 \%$ viability; was noticed at the concentration of $200 \mu \mathrm{g} / \mathrm{mL}$. Cell inhibition of $50 \%$ was observed by the addition of $250 \mu \mathrm{g} / \mathrm{mL}$ concentration of Cu NPs. In another study, Harne et al. [92], reported excellent viability against HeLa, A549 and BHK21 cells even at $120 \mu$ M concentration of Cu NPs.

Anticancer studies demonstrated the in vitro cytotoxicity value of $\mathrm{Cu}$ NPs against tested human colon cancer Caco- 2 cells, human hepatic cancer HepG2 cells and human breast cancer Mcf-7 cells.

Concerning human colon cancer $\mathrm{Caco} 2$, hepatic cancer HepG2, and breast cancer Mcf-7, the study conducted that $\mathrm{IC}_{50}$ for Cu-NPs was $11.21 \mu \mathrm{g} / \mathrm{mL}, 19.88 \mu \mathrm{g} / \mathrm{mL}$, and $12.21 \mu \mathrm{g} / \mathrm{mL}$. The provided results give promising predictions of Cu-NPs for using as anticancer for some of the human cancer in the near future [112].

Chakraborty and Basu [153] conducted that Cu NPs have a cytotoxic effect on different cancer cell lines viz., human skin melanoma A-375, human lung cancer A-549 and rat glioblastoma $\mathrm{C} 6-\mathrm{G}$. The $\mathrm{IC}_{50}$ dose against the A-375, A-549, and C6-G cells was found to be $1.71 \mu \mathrm{g} / \mathrm{mL}$, $1.81 \mu \mathrm{g} / \mathrm{mL}$ and $1.88 \mu \mathrm{g} / \mathrm{mL}$, respectively.

Albumin Cu NPs were synthesized by Azizi et al. [154] and it is found that prepared NPs have high toxicity against human breast cancer cells of MDA-MB 231 comparing to normal cells (MCF-10A) and apoptosis induction as the mechanism of cell death. Such findings revealed that these NPs are a good candidate to be used as a chemotherapeutic agent against invasive breast cancer cells.

In a study done by Chung et al. [155], cytotoxicity of $\mathrm{Cu}$ NPs against HepG2 cell lines was evaluated at 1, 10, 100, 250 and $500 \mu \mathrm{g} / \mathrm{mL}$. It was found that Cu NPs exhibited the cellular toxicity values of $3.0 \%, 15.5 \%, 28.5 \%, 44.5 \%$ and $54.5 \%$, for the same order of concentration; $1,10,100,250$ and $500 \mu \mathrm{g} / \mathrm{mL}$, respectively.

\section{Some other application of copper nanoparticles}

Due to $\mathrm{Cu}$ NPs unique physical and chemical properties, surface-to-volume ratio, low-cost preparation, and nontoxic preparation, Cu NPs have been of great interest recently. They have a great applications in different fields, for examples: Heat transfer systems [156], cytotoxicity "anticancer" activity [153], antimicrobial activity [78], antifungal activity [98, 102], super-strong materials [157], sensors [158], catalysts [57, 99], antioxidant activity $[100,159]$. Moreover, 0D NSMs, such as quantum dots has been extensively studied in light-emitting diodes (LEDs) [160], solar cells [161], single-electron transistors [162], and lasers [163], Dye degradation catalyst [164, $165]$ and anti fever mosquito as Aedes aegypti species [166].

\section{Analysis method}

The method of analysis used for the determination of the analyte amount may be either old fashion analysis methods or modern instrumental analysis methods. Titrations, Uv-Vis spectrophotometry, Spectrofluorimetric, Voltammetric, inductively coupled plasma, Chromatography as HPLC, GC; or any analysis method, it should be validated according to validation guidelines [167-169]. 


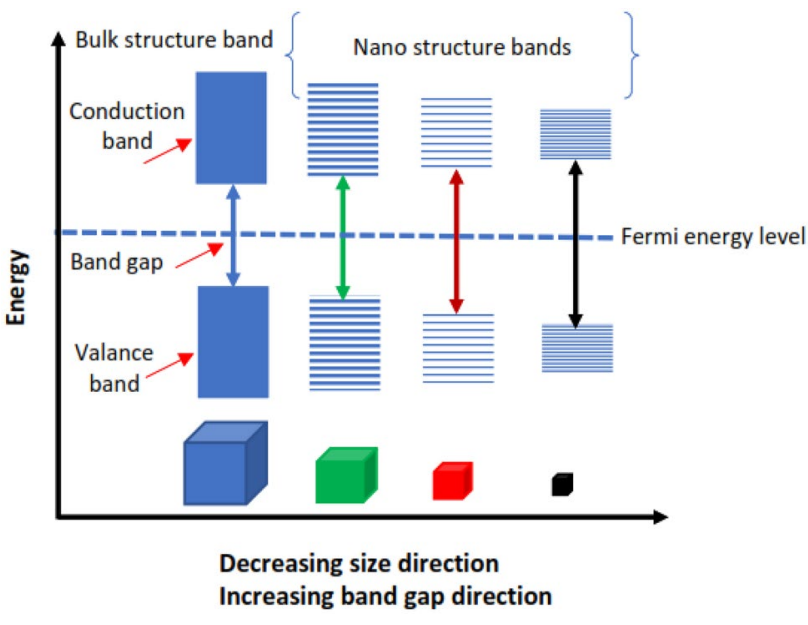

Fig. 10 Bulk, nano structure bands and their band gap relationship diagram

\section{Quantum condiment effect}

Quantum condiment means particles trapping and restrict their motion in dimension at dimension equal or less than $10 \mathrm{~nm}$ [170]. Quantum condiment effect gains its significant in the nano world according to the changes in the atomic structure as a result of ultra-small size of particle at nanoscale which directly affected the energy band structure. When the particle dimension is near to or below of any one of many possible length scales, such as the de Broglie wavelength of electrons or the photons wavelengths at high energy; these states make the materials properties size-dependent and their electronic "Blue shift in absorption by increasing of the exitonic transition energy "and optical properties "band gap" deviate actually from those of bulk materials [171].

For example, PbSe at size dimension $4.8 \mathrm{~nm}$ shows band gap at $0.82 \mathrm{eV}$ approximately, which exhibits strong quantum condiment effect with blue shift more than $0.5 \mathrm{eV}$ comparing with the $\mathrm{PbSe}$ at bulk state with band gap $0.28 \mathrm{eV}$ [172]. As a result of quantum condiment effect distortion of the continues bands into separately and distinct the atomic energy levels which subsequently leads to discrete in absorption spectrum while it was displayed continues in the bulk state absorption spectrum as in Fig. 10.

The more discrete energy levels can be found as a result of an increasing number of dimensions is confined or we can say, the movements of the electron and hole carriers is strongly confined in the given dimension.

The carrier's motion (electron and hole) are confined in one or more direction by barriers [173]. The quantum confined structure is classified according to the material dimensions as the following Table 6 and Fig. 11.
Table 6 Quantum confined structure classification

\begin{tabular}{lll}
\hline Structure & Quantum confinement & $\begin{array}{l}\text { Number of free } \\
\text { directions "dimen- } \\
\text { sions" }\end{array}$ \\
\hline Bulk states & 0 & 3 \\
Quantum wells/superlattices/thin films & 1 & 2 \\
Quantum wires & 2 & 1 \\
Quantum dots/nanocrystals & 3 & 0 \\
\hline
\end{tabular}

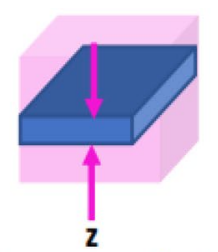

Quantum wells / superlattices/ thin films 2-dimensional material 1-dimensional confinement

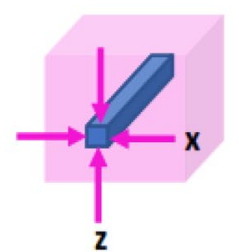

Quantum wires

1-dimensional material

2-dimensional confinement

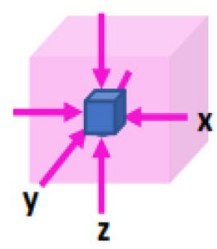

Quantum dots/ nanocrystals 0-dimensional material 3-dimensional confinement

Fig. 11 Quantum confined structure for different dimensions of material 
Acknowledgements The author presents great thanks to New Valley University. I'd like to introduce my great thanks to Dr. Reda Hassanein Prof. of the applied chemistry and Dr. Dalal Zein El-Abdeen Husein Prof. of the inorganic chemistry for their great notices and recommendations in reviewing my literature survey.

\section{Compliance with ethical standards}

Conflict of interest The corresponding author states that there is no conflict of interest.

\section{References}

1. Bhushan B (2017) Springer handbook of nanotechnology, 4th edn. Springer, Berlin

2. Dowling AP (2004) Development of nanotechnologies. Mater Today 7:30-35

3. Cameron N, Mitchell ME (2007) Nanoscale: issues and perspectives for the nano century. Wiley, New York

4. Schaming D, Remita H (2015) Nanotechnology: from the ancient time to nowadays. Found Chem 17:187-205

5. Sun Y, Xia Y (2003) Gold and silver nanoparticles: a class of chromophores with colors tunable in the range from 400 to $750 \mathrm{~nm}$. Analyst 128:686-691

6. Pidgeon N, Porritt J, Ryan J, Seaton A, Tendler S, Welland M and Whatmore R (2004) Nanoscience and nanotechnologies: opportunities and uncertainties. Royal Society

7. Fang M, Zeisberg W-M, Condon C, Ogryzko V, Danchin A, Mechold U (2009) Degradation of nanoRNA is performed by multiple redundant RNases in Bacillus subtilis. Nucleic Acids Res 37:5114

8. Ban K, Kocijancic S (2011). Introducing topics on nanotechnologies to middle and high school curricula. In: 2 nd world conference on technology and engineering education (5-8 September 2011, Ljubljana, Slovenia). Ljubljana

9. Keservani RK, Sharma AK (2019) Nanoparticulate drug delivery systems, 1st edn. Apple Academic Press, Warentown

10. Jeevanandam J, Barhoum A, Chan YS, Dufresne A, Danquah MK (2018) Review on nanoparticles and nanostructured materials: history, sources, toxicity and regulations. Beilstein J Nanotechnol 9:1050-1074

11. Fang X, Zhai T, Gautam UK, Li L, Wu L, Bando Y, Golberg D (2011) ZnS nanostructures: from synthesis to applications. Prog Mater Sci 56:175-287

12. Mardiansyah D, Triyana K, Sosiati H, Harsojo (2016) Synthesis of copper nanorods by aqueous solution method without heating external. In: AIP conference proceedings. AIP Publishing

13. Zeng N, Fan S, Ma J, Zhang Y, Zhang S, Zhang P, Zhang Z (2017) Synthesis and application of copper nanowires and silver nanosheet-coated copper nanowires as nanofillers in several polymers. Nanowires New Insights. https://doi. org/10.5772/67782

14. Luc W, Fu X, Shi J, Lv J-J, Jouny M, Ko BH, Xu Y, Tu Q, Hu X, Wu $J$, Yue Q, Liu Y, Jiao F, Kang Y (2019) Two-dimensional copper nanosheets for electrochemical reduction of carbon monoxide to acetate. Nat Cat 2:423-430

15. Gleiter $\mathrm{H}$ (2000) Nanostructured materials: basic concepts and microstructure. Acta Mater 48:1-29

16. Skorokhod V, Uvarova I, Ragulya A (2001) Physico-chemical kinetics in nanostructured systems. Kyiv Academperiodica $1: 180$
17. Pokropivny V, Skorokhod V (2007) Classification of nanostructures by dimensionality and concept of surface forms engineering in nanomaterial science. Mater Sci Eng C 27:990-993

18. Kim YT, Han JH, Hong BH, Kwon YU (2010) Electrochemical synthesis of CdSe quantum-dot arrays on a graphene basal plane using mesoporous silica thin-film templates. Adv Mater 22:515-518

19. Zhang G, Wang D (2008) Fabrication of heterogeneous binary arrays of nanoparticles via colloidal lithography. J Am Chem Soc 130:5616

20. Wang J, Lin M, Yan Y, Wang Z, Ho PC, Loh KP (2009) CdSe/AsS core-shell quantum dots: preparation and two-photon fluorescence. J Am Chem Soc 131:11300

21. Gautam UK, Vivekchand S, Govindaraj A, Kulkarni G, Selvi N, Rao C (2005) Generation of onions and nanotubes of GaS and GaSe through laser and thermally induced exfoliation. J Am Chem Soc 127:3658

22. Lee JY, Hong BH, Kim WY, Min SK, Kim Y, Jouravlev MV, Bose R, Kim KS, Hwang I-C, Kaufman LJ (2009) Near-field focusing and magnification through self-assembled nanoscale spherical lenses. Nature 460:498

23. Tiwari JN, Tiwari RN, Kim KS (2012) Zero-dimensional, onedimensional, two-dimensional and three-dimensional nanostructured materials for advanced electrochemical energy devices. Prog Mater Sci 57:724-803

24. Hochella MF, Spencer MG, Jones KL (2015) Nanotechnology: nature's gift or scientists' brainchild? Environ Sci Nano 2:114-119

25. Sharma VK, Filip J, Zboril R, Varma RS (2015) Natural inorganic nanoparticles-formation, fate, and toxicity in the environment. Chem Soc Rev 44:8410-8423

26. Wagner S, Gondikas A, Neubauer E, Hofmann T, von der Kammer $F$ (2014) Spot the difference: engineered and natural nanoparticles in the environment-release, behavior, and fate. Angew Chem Int Ed 53:12398-12419

27. Zhang Q-I, Yang Z-m, Ding B-j, Lan X-z, Guo Y-j (2010) Preparation of copper nanoparticles by chemical reduction method using potassium borohydride. Trans Nonferrous Met Soc China 20:s240-s244

28. Zhu X, Wang B, Shi F, Nie J (2012) Direct, rapid, facile photochemical method for preparing copper nanoparticles and copper patterns. Langmuir 28:14461-14469

29. Han W-K, Choi J-W, Hwang G-H, Hong S-J, Lee J-S, Kang S-G (2006) Fabrication of $\mathrm{Cu}$ nano particles by direct electrochemical reduction from $\mathrm{CuO}$ nano particles. Appl Surf Sci 252:2832-2838

30. Betancourt-Galindo R, Reyes-Rodriguez $P$, Puente-Urbina $B$, Avila-Orta C, Rodríguez-Fernández O, Cadenas-Pliego G, LiraSaldivar R, García-Cerda L (2014) Synthesis of copper nanoparticles by thermal decomposition and their antimicrobial properties. J Nanomater 2014:10

31. Delma B, Vijila B, Jaya M (2016) Green synthesis of copper and lead nanoparticles using zingiber officinale stem extract. Int J Sci Res Publ 6:134-137

32. Abd-Elkareem Jl, Bassuony HM, Mohammed SM, Fahmy HM, Abd-Elkader NR (2016) Eco-friendly methods of copper nanoparticles synthesis. J Bionanosci 10:15-37

33. El-Refai AA, Ghoniem GA, El-Khateeb AY, Hassaan MM (2018) Eco-friendly synthesis of metal nanoparticles using ginger and garlic extracts as biocompatible novel antioxidant and antimicrobial agents. J Nanostruct Chem 8:71-81

34. Caroling G, Vinodhini E, Ranjitham AM, Shanthi P (2015) Biosynthesis of copper nanoparticles using aqueous Phyllanthus embilica (Gooseberry) extract-characterisation and study of antimicrobial effects. Int J Nano Chem 1:53-63 
35. Ahmad N, Sharma S, Alam MK, Singh V, Shamsi S, Mehta B, Fatma A (2010) Rapid synthesis of silver nanoparticles using dried medicinal plant of basil. Colloids Surf B 81:81-86

36. Kumar V, Yadav SK (2011) Synthesis of stable, polyshaped silver, and gold nanoparticles using leaf extract of Lonicera japonica L. Int J Green Nanotechnol 3:281-291

37. Si S, Mandal TK (2007) Tryptophan-based peptides to synthesize gold and silver nanoparticles: a mechanistic and kinetic study. Chem Eur J 13:3160-3168

38. Kasthuri J, Veerapandian S, Rajendiran N (2009) Biological synthesis of silver and gold nanoparticles using apiin as reducing agent. Colloids Surf B 68:55-60

39. Peralta-Videa JR, Huang Y, Parsons JG, Zhao L, Lopez-Moreno L, Hernandez-Viezcas JA, Ardea-Torresdey JL (2016) Plant-based green synthesis of metallic nanoparticles: scientific curiosity or a realistic alternative to chemical synthesis? Nano Environ Eng $1: 4$

40. Shah M, Fawcett D, Sharma S, Tripathy S, Poinern G (2015) Green synthesis of metallic nanoparticles via biological entities. Materials 8:7278-7308

41. Malik P, Shankar R, Malik V, Sharma N, Mukherjee TK (2014) Green chemistry based benign routes for nanoparticle synthesis. J Nanopart. https://doi.org/10.1155/2014/302429

42. Duan H, Wang D, Li Y (2015) Green chemistry for nanoparticle synthesis. Chem Soc Rev 44:5778-5792

43. Jha AK, Prasad K (2012) Biosynthesis of gold nanoparticles using common aromatic plants. Int J Green Nanotechnol 4:219-224

44. Sheny D, Mathew J, Philip D (2012) Synthesis characterization and catalytic action of hexagonal gold nanoparticles using essential oils extracted from Anacardium occidentale. Spectrochim Acta Part A 97:306-310

45. Kahrilas GA, Wally LM, Fredrick SJ, Hiskey M, Prieto AL, Owens JE (2013) Microwave-assisted green synthesis of silver nanoparticles using orange peel extract. ACS Sustain Chem Eng 2:367-376

46. Dwivedi P, Narvi SS, Tewari RP (2012) Rudraksha assisted generation of silver nanoparticles for integrated application in the biomedical landscape. Int J Green Nanotechnol 4:248-261

47. Bar H, Bhui DK, Sahoo GP, Sarkar P, De SP, Misra A (2009) Green synthesis of silver nanoparticles using latex of Jatropha curcas. Colloids Surf A 339:134-139

48. Sathishkumar M, Sneha K, Won S, Cho C-W, Kim S, Yun Y-S (2009) Cinnamon zeylanicum bark extract and powder mediated green synthesis of nano-crystalline silver particles and its bactericidal activity. Colloids Surf B 73:332-338

49. Noruzi M, Zare D, Khoshnevisan K, Davoodi D (2011) Rapid green synthesis of gold nanoparticles using Rosa hybrida petal extract at room temperature. Spectrochim Acta Part A 79:1461-1465

50. Pasca R-D, Mocanu A, Cobzac S-C, Petean I, Horovitz O, Tomoaia-Cotisel M (2014) Biogenic syntheses of gold nanoparticles using plant extracts. Part Sci Technol 32:131-137

51. Gowramma B, Keerthi U, Rafi M, Rao DM (2015) Biogenic silver nanoparticles production and characterization from native stain of Corynebacterium species and its antimicrobial activity. 3 Biotech 5:195-201

52. Makarov V, Love A, Sinitsyna O, Makarova S, Yaminsky I, Taliansky M, Kalinina N (2014) "Green" nanotechnologies: synthesis of metal nanoparticles using plants. Acta Nat 6:35-44

53. Rekulapally SR (2014) Synthesis and characterization of nanoparticles capped with medicinal plant extracts. Texas A\&M University-Kingsville

54. Li D, Müller MB, Gilje S, Kaner RB, Wallace GG (2008) Processable aqueous dispersions of graphene nanosheets. Nat Nanotechnol 3:101-105
55. Thakur S, Sharma S, Thakur S, Rai R (2018) Green synthesis of copper nano-particles using Asparagus adscendens roxb. Root and leaf extract and their antimicrobial activities. Int J Curr Microbiol Appl Sci 7:683-694

56. Nasrollahzadeh M, Sajadi SM, Khalaj M (2014) Green synthesis of copper nanoparticles using aqueous extract of the leaves of Euphorbia esula $\mathrm{L}$ and their catalytic activity for ligand-free Ullmann-coupling reaction and reduction of 4-nitrophenol. RSC Adv 4:47313-47318

57. Nasrollahzadeh M, Mohammad Sajadi S (2015) Green synthesis of copper nanoparticles using Ginkgo biloba L. leaf extract and their catalytic activity for the Huisgen [3+2] cycloaddition of azides and alkynes at room temperature. J Colloid Interface Sci 457:141-147

58. Ichiyanagi Y, Uehashi T, Yamada S (2004) Magnetic properties of $\mathrm{Ni}-\mathrm{Zn}$ ferrite nanoparticles. Phys Status Solidi 1:3485-3488

59. Mathur $P$, Thakur A, Singh M (2008) Effect of nanoparticles on the magnetic properties of $\mathrm{Mn}-\mathrm{Zn}$ soft ferrite. J Magn Magn Mater 320:1364-1369

60. Chen JP, Sorensen CM, Klabunde KJ, Hadjipanayis GC, Devlin E, Kostikas A (1996) Size-dependent magnetic properties of fine particles synthesized by coprecipitation. Phys Rev B 54:9288-9296

61. Guedidi H, Reinert L, Soneda Y, Bellakhal N, Duclaux L (2017) Adsorption of ibuprofen from aqueous solution on chemically surface-modified activated carbon cloths. Arab J Chem 10:S3584-S3594

62. Hu X, Cheng Z, Sun Z, Zhu H (2017) Adsorption of diclofenac and triclosan in aqueous solution by purified multi-walled carbon nanotubes. Pol J Environ Stud 26:87-95

63. Husein DZ, Hassanien R, Al-Hakkani MF (2019) Green-synthesized copper nano-adsorbent for the removal of pharmaceutical pollutants from real wastewater samples. Heliyon 5:e02339. https://doi.org/10.1016/j.heliyon.2019.e02339

64. Sarıcı-Özdemir Ç, Önal Y, Erdoğan S, Akmil-Başar C (2012) Studies on removal of naproxen sodium by adsorption onto ACF in batch and column. Fresenius Environ Bull 21:1-6

65. Jodeh S, Abdelwahab F, Jaradat N, Warad I, Jodeh W (2016) Adsorption of diclofenac from aqueous solution using Cyclamen persicum tubers based activated carbon (CTAC). J Assoc Arab Univ Basic Appl Sci 20:32-38

66. Egziabher G (2012) Biosynthesis of copper nanoparticles using some plant leaf extracts, their characterization and anti-bacterial activity in Physical Chemistry. Haramaya University

67. Dollwet $\mathrm{H}$ (2001) Historic uses of copper compounds in medicine. Trace Elem Med 2:80-87

68. Goyer RA (1997) Toxic and essential metal interactions. Annu Rev Nutr 17:37-50

69. Airey P, Verran J (2007) Potential use of copper as a hygienic surface; problems associated with cumulative soiling and cleaning. J Hosp Infect 67:271-277

70. Mehtar S, Wiid I, Todorov S (2008) The antimicrobial activity of copper and copper alloys against nosocomial pathogens and Mycobacterium tuberculosis isolated from healthcare facilities in the Western Cape: an in vitro study. J Hosp Infect 68:45-51

71. Smith AM, Duan H, Rhyner MN, Ruan G, Nie S (2006) A systematic examination of surface coatings on the optical and chemical properties of semiconductor quantum dots. Phys Chem Chem Phys 8:3895-3903

72. Theivasanthi T, Alagar M (2011) Studies of copper nanoparticles effects on micro-organisms. Cornell University

73. Jeong S, Woo K, Kim D, Lim S, Kim JS, Shin H, Xia Y, Moon J (2008) Controlling the thickness of the surface oxide layer on Cu nanoparticles for the fabrication of conductive structures by ink-jet printing. Adv Funct Mater 18:679-686 
74. Dadgostar N (2008) Investigations on colloidal synthesis of copper nanoparticles in a two-phase liquid-liquid system. University of Waterloo

75. Yabuki A, Arriffin N (2010) Electrical conductivity of copper nanoparticle thin films annealed at low temperature. Thin Solid Films 518:7033-7037

76. Mott D, Galkowski J, Wang L, Luo J, Zhong C-J (2007) Synthesis of size-controlled and shaped copper nanoparticles. Langmuir 23:5740-5745

77. Khanna P, Gaikwad S, Adhyapak P, Singh N, Marimuthu R (2007) Synthesis and characterization of copper nanoparticles. Mater Lett 61:4711-4714

78. Esteban-Cubillo A, Pecharromán C, Aguilar E, Santarén J, Moya JS (2006) Antibacterial activity of copper monodispersed nanoparticles into sepiolite. J Mater Sci 41:5208-5212

79. Habibi MH, Kamrani R, Mokhtari R (2010) Fabrication and characterization of copper nanoparticles using thermal reduction: the effect of nonionic surfactants on size and yield of nanoparticles. Microchim Acta 171:91-95

80. Ponce AA, Klabunde KJ (2005) Chemical and catalytic activity of copper nanoparticles prepared via metal vapor synthesis. J Mol Catal A Chem 225:1-6

81. Joshi S, Patil S, lyer V, Mahumuni S (1998) Radiation induced synthesis and characterization of copper nanoparticles. Nanostruct Mater 10:1135-1144

82. Qi L, Ma J, Shen J (1997) Synthesis of copper nanoparticles in nonionic water-in-oil microemulsions. J Colloid Interface Sci 186:498-500

83. Tilaki R, Mahdavi S (2007) Size, composition and optical properties of copper nanoparticles prepared by laser ablation in liquids. Appl Phys A 88:415-419

84. DeCastro CL, Mitchell BS (2002) Nanoparticles from mechanical attrition. Syn Func Surf Treat Nano 1-15

85. Dang TMD, Le TTT, Fribourg-Blanc E, Dang MC (2011) Synthesis and optical properties of copper nanoparticles prepared by a chemical reduction method. Adv Nat Sci Nanosci Nanotechnol 2:015009

86. Shantkriti S, Rani P (2014) Biological synthesis of copper nanoparticles using Pseudomonas fluorescens. Int J Curr Microbiol Appl Sci 3:374-383

87. Salvadori MR, Ando RA, Oller Do Nascimento CA, Corrêa B (2014) Bioremediation from wastewater and extracellular synthesis of copper nanoparticles by the fungus Trichoderma koningiopsis. J Environ Sci Health Part A 49:1286-1295

88. Singh S (2017) Green approach towards synthesis of copper nanoparticles: a review. Int J Innov Emerg 4:162-170

89. Valodkar M, Nagar PS, Jadeja RN, Thounaojam MC, Devkar RV, Thakore S (2011) Euphorbiaceae latex induced green synthesis of non-cytotoxic metallic nanoparticle solutions: a rational approach to antimicrobial applications. Colloids Surf A 384:337-344

90. Valodkar M, Jadeja RN, Thounaojam MC, Devkar RV, Thakore S (2011) Biocompatible synthesis of peptide capped copper nanoparticles and their biological effect on tumor cells. Mater Chem Phys 128:83-89

91. Lee H-J, Lee G, Jang NR, Yun JH, Song JY, Kim BS (2011) Biological synthesis of copper nanoparticles using plant extract. Nanotechnology 1:371-374

92. Harne S, Sharma A, Dhaygude M, Joglekar S, Kodam K, Hudlikar M (2012) Novel route for rapid biosynthesis of copper nanoparticles using aqueous extract of Calotropis procera L. latex and their cytotoxicity on tumor cells. Colloids Surf B 95:284-288

93. Subhankari I, Nayak P (2013) Antimicrobial activity of copper nanoparticles synthesised by ginger (Zingiber officinale) extract. World J Nano Sci Technol 2:10-13
94. Subhankari I, Nayak P (2013) Synthesis of copper nanoparticles using Syzygium aromaticum (Cloves) aqueous extract by using green chemistry. World J Nano Sci Technol 2:14-17

95. Saranyaadevi K, Subha V, Ravindran RE, Renganathan S (2014) Synthesis and characterization of copper nanoparticle using Capparis zeylanica leaf extract. Int J Chem Technol Res 6:4533-4541

96. Angrasan J, Subbaiya R (2014) Biosynthesis of copper nanoparticles by Vitis vinifera leaf aqueous extract and its antibacterial activity. Int J Curr Microbiol Appl Sci 3:768-774

97. Gopinath M, Subbaiya R, Selvam MM, Suresh D (2014) Synthesis of copper nanoparticles from Nerium oleander leaf aqueous extract and its antibacterial activity. Int J Curr Microbiol Appl Sci 3:814-818

98. Ranjitham AM, Ranjani GS, Caroling G (2015) Biosynthesis, characterization, antimicrobial activity of copper nanoparticles using fresh aqueous Ananas comosus L. (Pineapple) extract. Int J PharmTech Res 8:750-769

99. Sinha T, Ahmaruzzaman M (2015) Biogenic synthesis of Cu nanoparticles and its degradation behavior for methyl red. Mater Lett 159:168-171

100. Subbaiya R, Selvam MM (2015) Green synthesis of copper nanoparticles from Hibicus rosasinensis and their antimicrobial, antioxidant activities. J Chem Pharm Res 6:1183-1190

101. Caroling G, Priyadharshini MN, Vinodhini E, Ranjitham AM, Shanthi P (2015) Biosynthesis of copper nanoparticles using aqueous guava extract-characterization and study of antibacterial effects. Int J Pharm Biol Sci 5:25-43

102. Jayandran M, Haneefa MM, Balasubramanian V (2015) Green synthesis of copper nanoparticles using natural reducer and stabilizer and an evaluation of antimicrobial activity. J Chem Pharm Res 7:251-259

103. Karimi J, Mohsenzadeh S (2015) Rapid, green, and eco-friendly biosynthesis of copper nanoparticles using flower extract of Aloe vera. Synth React Inorg Met Org Nano-Met Chem 45:895-898

104. Kalpana V, Chakraborthy P, Palanichamy V, Rajeswari VD (2016) Synthesis and characterization of copper nanoparticles using Tridax procumbens and its application in degradation of bismarck brown. Int J ChemTech Res 9:498-507

105. Hariprasad S, Bai GS, Santhoshkumar J, Madhu C, Sravani D (2016) Greensynthesis of copper nanoparticles by arevalanata leaves extract and their anti microbial activites. Int J ChemTech Res 9:98-105

106. Kala A, Soosairaj S, Mathiyazhagan S, Raja P (2015) Green synthesis of copper bionanoparticles to control the bacterial leaf blight disease of rice. Curr Sci 110:2011-2014

107. Kaur P, Thakur R, Chaudhury A (2016) Biogenesis of copper nanoparticles using peel extract of Punica granatum and their antimicrobial activity against opportunistic pathogens. Green Chem Lett Rev 9:33-38

108. Valli G, Geetha S (2016) Green synthesis of copper nanoparticles using Cassia auriculata leaves extract. Int J Tech Chem Rec 2:05-10

109. Joseph AT, Prakash P, Narvi S (2016) Phytofabrication and characterization of copper nanoparticles using Allium sativum and its antibacterial activity. Int J Sci Eng Technol 4:463-472

110. Nasrollahzadeh M, Momeni SS, Sajadi SM (2017) Green synthesis of copper nanoparticles using Plantago asiatica leaf extract and their application for the cyanation of aldehydes using K4Fe (CN) 6. J Colloid Interface Sci 506:471-477

111. Ananthi P, Kala SMJ (2017) Plant extract mediated synthesis and characterization of copper nanoparticles and their pharmacological activities. Int J Innov Res Sci Eng Technol 6:13455-13465

112. Hassanien R, Husein DZ, Al-Hakkani MF (2018) Biosynthesis of copper nanoparticles using aqueous Tilia extract: antimicrobial 
and anticancer activities. Heliyon 4:e01077. https://doi. org/10.1016/j.heliyon.2018.e01077

113. Padma PN, Banu ST, Kumari SC (2018) Studies on green synthesis of copper nanoparticles using Punica granatum. Annu Res Rev Biol 23:1-10

114. Rajesh K, Ajitha B, Reddy YAK, Suneetha Y, Reddy PS (2018) Assisted green synthesis of copper nanoparticles using Syzygium aromaticum bud extract: physical, optical and antimicrobial properties. Optik 154:593-600

115. Nagar N, Devra V (2018) Green synthesis and characterization of copper nanoparticles using Azadirachta indica leaves. Mater Chem Phys 213:44-51

116. Ismail M, Gul S, Khan M, Khan MA, Asiri AM, Khan SB (2019) Green synthesis of zerovalent copper nanoparticles for efficient reduction of toxic azo dyes congo red and methyl orange. Green Process Synth 8:135-143

117. Jamdade DA, Rajpali D, Joshi KA, Kitture R, Kulkarni AS, Shinde VS, Bellare J, Babiya KR, Ghosh S (2019) Gnidia glauca-and plumbago zeylanica-mediated synthesis of novel copper nanoparticles as promising antidiabetic agents. Adv Pharmacol Sci. https://doi.org/10.1155/2019/9080279

118. Sharma P, Pant S, Dave V, Tak K, Sadhu V, Reddy KR (2019) Green synthesis and characterization of copper nanoparticles by Tinospora cordifolia to produce nature-friendly copper nano-coated fabric and their antimicrobial evaluation. J Microbiol Methods 160:107-116

119. Xia Y, Halas NJ (2005) Shape-controlled synthesis and surface plasmonic properties of metallic nanostructures. MRS Bull 30:338-348

120. Alharbi R, Irannejad M, Yavuz M (2019) A short review on the role of the metal-graphene hybrid nanostructure in promoting the localized surface plasmon resonance sensor performance. Sensors 19:862

121. West PR, Ishii S, Naik GV, Emani NK, Shalaev VM, Boltasseva AJL (2010) Searching for better plasmonic materials. Laser Photon Rev 4:795-808

122. Johnson PB, Christy R-W (1972) Optical constants of the noble metals. Phys Rev B 6:4370

123. Marton J, Jordan B (1977) Optical properties of aggregated metal systems: interband transitions. Phys Rev B 15:1719

124. Liu P, Wang H, Li X, Rui M, Zeng H (2015) Localized surface plasmon resonance of $\mathrm{Cu}$ nanoparticles by laser ablation in liquid media. RSC Adv 5:79738-79745

125. Chan GH, Zhao J, Hicks EM, Schatz GC, Van Duyne RP (2007) Plasmonic properties of copper nanoparticles fabricated by nanosphere lithography. Nano Lett 7:1947-1952

126. Singh M, Goyal M, Devlal K (2018) Size and shape effects on the band gap of semiconductor compound nanomaterials. J Taibah Univ Sci 12:470-475

127. Schulz F (2013) Electronic and optical properties of nanomaterials, in Physics Department. University of Osnabrueck

128. Weller H (1993) Quantized semiconductor particles: a novel state of matter for materials science. Adv Mater 5:88-95

129. Alzahrani E, Ahmed RA (2016) Synthesis of copper nanoparticles with various sizes and shapes: application as a superior non-enzymatic sensor and antibacterial agent. Int J Electrochem Sci 11:4712-4723

130. Mohindru JJ, Garg UK (2017) Green synthesis of copper nanoparticles using tea leaf extract. Int J Eng Sci Res Technol 6:307-311

131. Papavassiliou G, Kokkinakis T (1974) Optical absorption spectra of surface plasmons in small copper particles. J Phys F Met Phys 4:L67

132. Suresh Sagadevan KP (2015) Analysis of structure, surface morphology, optical and electrical properties of copper nanoparticles. Nanomed Res 2:40
133. Quaschning V (2016) Understanding renewable energy systems. Routledge, Abingdon

134. Srensen B (2004) Renewable energy: its physics, engineering, use, environmental impacts, economy, and planning aspects. Elsevier Academic Press, Amsterdam

135. Fendler JH (2008) Nanoparticles and nanostructured films: preparation, characterization, and applications. Wiley, New York

136. Mooradian A (1969) Photoluminescence of metals. Phys Rev Lett 22:185

137. Plekhanov V, Silukova T (1990) Experimental manifestation of the d-band structure in the photoluminescence spectra of gold. Soviet Phys Solid State 32:1268

138. Siwach OP, Sen $P$ (2008) Synthesis and study of fluorescence properties of Cu nanoparticles. J Nanopart Res 10:107-114

139. Das R, Nath SS, Bhattacharjee R (2011) Luminescence of copper nanoparticles. J Lumin 131:2703-2706

140. Hu R, Liu Y-R, Kong R-M, Donovan MJ, Zhang X-B, Tan W, Shen G-L, Yu R-Q (2013) Double-strand DNA-templated formation of copper nanoparticles as fluorescent probe for label free nuclease enzymedetection. Biosens Bioelectron 42:31-35

141. Wang C, Wang C, Xu L, Cheng H, Lin Q, Zhang C (2014) Protein-directed synthesis of $\mathrm{pH}$-responsive red fluorescent copper nanoclusters and their applications in cellular imaging and catalysis. Nanoscale 6:1775-1781

142. Bhamore JR, Jha S, Mungara AK, Singhal RK, Sonkeshariya D, Kailasa SK (2016) One-step green synthetic approach for the preparation of multicolor emitting copper nanoclusters and their applications in chemical species sensing and bioimaging. Biosens Bioelectron 80:243-248

143. Suresh Y, Annapurna S, Bhikshamaiah G, Singh A (2016) Green luminescent copper nanoparticles. IOP Conf Ser Mater Sci Eng 149:012187

144. Andolina CM, Crawford SE, Smith AM, Johnston KA, Straney PJ, Marbella LE, Tolman NL, Hochuli TJ, Millstone JE (2018) Nearinfrared photoluminescence from small copper, silver, and gold nanoparticles. ChemNanoMat 4:265-268

145. Gui R, Sun J, Cao X, Wang Y, Jin H (2014) Multidentate polymers stabilized water-dispersed copper nanoclusters: facile photoreduction synthesis and selective fluorescence turn-on response. RSC Adv 4:29083-29088

146. Lee Y, Choi J-r, Lee KJ, Stott NE, Kim D (2008) Large-scale synthesis of copper nanoparticles by chemically controlled reduction for applications of inkjet-printed electronics. Nanotechnology 19:415604

147. Tamilvanan A, Balamurugan K, Ponappa K, Kumar BM (2014) Copper nanoparticles: synthetic strategies, properties and multifunctional application. Int J Nanosci 13:1430001

148. Kela LA, Ari T, Unto H, Jouni M (2014) nanoparticles for conductive inks in International Congress of Metallurgy and Materials, SAMCONAMET/IBEROMAT 2014. Santa Fe, Argentina

149. Paixão RM, Reck IM, Bergamasco R, Vieira MF, Vieira AMS (2018) Activated carbon of Babassu coconut impregnated with copper nanoparticles by green synthesis for the removal of nitrate in aqueous solution. Environ Technol 39:1994-2003

150. Oliveira LM, Nascimento MA, Guimarães YM, Oliveira AF, Silva AA, Lopes RP (2018) Removal of beta-lactams antibiotics through zero-valent copper nanoparticles. J Braz Chem Soc 29:1630-1637

151. Saranya R, Ali MM (2017) Synthesis of colloidal copper nanoparticles and its cytotoxicity effect on MCF-7 breast cancer cell lines. J Chem Pharm Sci 974:1-5

152. Woźniak-Budych MJ, Przysiecka Ł, Langer K, Peplińska B, Jarek M, Wiesner M, Nowaczyk G, Jurga S (2017) Green synthesis of rifampicin-loaded copper nanoparticles with enhanced antimicrobial activity. J Mater Sci Mater Med 28:42 
153. Chakraborty R, Basu T (2017) Metallic copper nanoparticles induce apoptosis in a human skin melanoma A-375 cell line. Nanotechnology 28:105101

154. Azizi M, Ghourchian H, Yazdian F, Dashtestani F, AlizadehZeinabad $\mathrm{H}$ (2017) Cytotoxic effect of albumin coated copper nanoparticle on human breast cancer cells of MDA-MB 231. PLoS ONE 12:e0188639

155. Chung I, Abdul Rahuman A, Marimuthu S, Vishnu Kirthi A, Anbarasan K, Padmini P, Rajakumar G (2017) Green synthesis of copper nanoparticles using Eclipta prostrata leaves extract and their antioxidant and cytotoxic activities. Exp Ther Med $14: 18-24$

156. Eastman JA, Choi S, Li S, Yu W, Thompson L (2001) Anomalously increased effective thermal conductivities of ethylene glycolbased nanofluids containing copper nanoparticles. Appl Phys Lett 78:718-720

157. Guduru RK, Murty KL, Youssef KM, Scattergood RO, Koch CC (2007) Mechanical behavior of nanocrystalline copper. Mater Sci Eng A 463:14-21

158. Kang X, Mai Z, Zou X, Cai P, Mo J (2007) A sensitive nonenzymatic glucose sensor in alkaline media with a copper nanocluster/multiwall carbon nanotube-modified glassy carbon electrode. Anal Biochem 363:143-150

159. Kalpana V, Chakraborthy P, Palanichamy V, Rajeswari VD (2016) Synthesis and characterization of copper nanoparticles using Tridax procumbens and its application in degradation of bismarck brown. Int J ChemTech Res 10:17

160. Stouwdam JW, Janssen RA (2008) Red, green, and blue quantum dot LEDs with solution processable $\mathrm{ZnO}$ nanocrystal electron injection layers. J Mater Chem 18:1889

161. Lee W, Kang SH, Kim J-Y, Kolekar GB, Sung Y-E, Han S-H (2009) $\mathrm{TiO} 2$ nanotubes with a $\mathrm{ZnO}$ thin energy barrier for improved current efficiency of CdSe quantum-dot-sensitized solar cells. Nanotechnology 20:335706

162. Mokerov V, Fedorov YV, Velikovski L, Scherbakova MY (2001) New quantum dot transistor. Nanotechnology 12:552

163. Ustinov V, Zhukov A, Kovsh A, Mikhrin S, Maleev N, Volovik B, Musikhin YG, Shernyakov YM, Kondat'eva EY, Maximov M (2000) Long-wavelength quantum dot lasers on GaAs substrates. Nanotechnology 11:397
164. Niharika N, Vijay D (2017) Activation of peroxodisulfate and peroxomonosulfate by green synthesized copper nanoparticles for Methyl Orange degradation: a kinetic study. J Environ Chem Eng 5:5793-5800

165. Niharika N, Vijay D (2018) Oxidative degradation of Orange G by peroxomonosulfate in presence of biosynthesized copper nanoparticles-a kinetic study. Environ Technol Innov 10:281-289

166. Selvan SM, Anand KV, Govindaraju K, Tamilselvan S, Kumar VG, Subramanian K, Sevathapandian Kannan M, Raja K (2018) Green synthesis of copper oxide nanoparticles and mosquito larvicidal activity against dengue, zika and chikungunya causing vector Aedes aegypti. IET Nanobiotechnol 12:1042-1046

167. Al-Hakkani MF (2019) Guideline of inductively coupled plasma mass spectrometry "ICP-MS": fundamentals, practices, determination of the limits, quality control, and method validation parameters. SN Appl Sci 1:791. https://doi.org/10.1007/s4245 2-019-0825-5

168. Al-Hakkani MF (2019) A rapid, developed and validated RPHPLC method for determination of azithromycin. SN Appl Sci 1:222. https://doi.org/10.1007/s42452-019-0237-6

169. Al-Hakkani MF (2019) Forced degradation study with a developed and validated RP-HPLC method for determination of cefpodoxime proxetil in the bulk and finished pharmaceutical products. J Iran Chem Soc 16:1571-1578. https://doi. org/10.1007/s13738-019-01630-5

170. Takagahara T, Takeda K (1992) Theory of the quantum confinement effect on excitons in quantum dots of indirect-gap materials. Phys Rev B 46:15578-15581

171. Yoffe AD (1993) Low-dimensional systems: quantum size effects and electronic properties of semiconductor microcrystallites (zero-dimensional systems) and some quasi-two-dimensional systems. J Adv Phys 42:173-262

172. Wise FW (2000) Lead salt quantum dots: the limit of strong quantum confinemen. Acc Chem Res 33:773-780

173. Neikov OD, Yefimov NA (2019) Handbook of non-ferrous metal powders, 2nd edn. Elsevier, Amsterdam

Publisher's Note Springer Nature remains neutral with regard to jurisdictional claims in published maps and institutional affiliations. 